Research Paper

\title{
MUC3A promotes non-small cell lung cancer progression via activating the NFKB pathway and attenuates radiosensitivity
}

\author{
Yingming Sun ${ }^{1,2 \#, ~ X i a o g e ~ S u n ~}{ }^{1,3 \#}$, Chengcheng You ${ }^{1,4}$, Shijing Ma1, Yuan Luo ${ }^{1}$, Shan Peng1, Fang Tang1, \\ Xiaoli Tian'1, Feng Wang1, Zhengrong Huang1,5, Hongnv Yu ${ }^{6}$, Yu Xiao ${ }^{5,7}$, Xiaoyong Wang1,8, Junhong \\ Zhang ${ }^{1,8}$, Yan Gong $5,7 \bowtie$, Conghua Xie ${ }^{1,8} \bowtie$ \\ 1. Department of Radiation and Medical Oncology, Zhongnan Hospital of Wuhan University, Wuhan, China. \\ 2. Department of Radiation and Medical Oncology, Affiliated Sanming First Hospital of Fujian Medical University, Sanming, China. \\ 3. Department of Radiation Oncology, The Affiliated Hospital of Inner Mongolia Medical University, Hohhot, China. \\ 4. Department of Pathology, China Three Gorges University Medical College, Yichang, China. \\ 5. Department of Biological Repositories, Zhongnan Hospital of Wuhan University, Wuhan, China \\ 6. Central Laboratory of Xinhua Hospital of Dalian University, Department of Medical Oncology, Xinhua Hospital of Dalian University, Dalian, China. \\ 7. Tumor Precision Diagnosis and Treatment Technology and Translational Medicine, Hubei Engineering Research Center, Zhongnan Hospital of Wuhan \\ University, Wuhan, China. \\ 8. Hubei Key Laboratory of Tumor Biological Behaviors, Hubei Cancer Clinical Study Center, Zhongnan Hospital of Wuhan University, Wuhan, China
}

\#These authors contributed equally to this work.

$\triangle$ Corresponding authors: Conghua Xie, Department of Radiation and Medical Oncology, Zhongnan Hospital of Wuhan University, Wuhan, Hubei 430071, China, Phone: +86-27-67812607, Email: chxie_65@whu.edu.cn; and Yan Gong, Department of Biological Repositories, Zhongnan Hospital of Wuhan University, Wuhan, Hubei 430071, China, Phone: +86-27-67811461, Email: yan.gong@whu.edu.cn.

(c) The author(s). This is an open access article distributed under the terms of the Creative Commons Attribution License (https://creativecommons.org/licenses/by/4.0/). See http://ivyspring.com/terms for full terms and conditions.

Received: 2021.02.15; Accepted: 2021.05.20; Published: 2021.06.16

\begin{abstract}
Mucin 3A (MUC3A) is highly expressed in non-small cell lung cancer (NSCLC), but its functions and effects on clinical outcomes are not well understood. Tissue microarray of 92 NSCLC samples indicated that high levels of MUC3A were associated with poor prognosis, advanced staging, and low differentiation. MUC3A knockdown significantly suppressed NSCLC cell proliferation and induced G1/S accumulation via downregulating cell cycle checkpoints. MUC3A knockdown also inhibited tumor growth in vivo and had synergistic effects with radiation. MUC3A knockdown increased radiation-induced DNA double strain breaks and $\mathrm{Y}-\mathrm{H} 2 \mathrm{AX}$ phosphorylation in NSCLC cells. MUC3A downregulation inhibited the BRCA-1/RAD51 pathway and nucleus translocation of P53 and XCRR6, suggesting that MUC3A promoted DNA damage repair and attenuated radiation sensitivity. MUC3A knockdown also resulted in less nucleus translocation of RELA and P53 in vivo. Immunoprecipitation revealed that MUC3A interacted with RELA and activated the NFKB pathway via promoting RELA phosphorylation and interfering the binding of RELA to IKB. Our studies indicated that MUC3A was a potential oncogene and associated with unfavorable clinical outcomes. NSCLC patients with a high MUC3A level, who should be more frequent follow-up and might benefit less from radiotherapy.
\end{abstract}

Key words: MUC3A; NSCLC; NFkB; Radiosensitivity; DNA damage

\section{Introduction}

Non-small cell lung cancer (NSCLC) is one of the most common human malignancies with high mortality rate over the past 30 years [1]. Approximately $60 \%$ of NSCLC patients are diagnosed at advanced stages, and half need radiotherapy during their treatment course. Local control after radiotherapy weights the most to survival benefit
[2-5]. The ultimate goal of radiotherapy is a highdose-delivery in the target without radiation-induced injuries in the surrounding normal tissues [6]. Previous clinical trials indicate that a radiation dose of $>84$ Gray (Gy) is required for 50\% tumor control within 3 years [7]. Although enormous radiotherapeutic techniques boost recently [8], the 
therapeutic effects of radiotherapy are still unsatisfactory. The 5-years survival rate of NSCLC is only $16.1 \%[9,10]$. Therefore, it is urgent to promote the biological effects of radiation and find a reliable index to predict radiotherapy effects.

Many mucins are reported as biomarkers to identify and monitor the progression of lung cancer. It is aberrantly expressed in NSCLC cells and participates in tumor progression and metastasis via altering various signalling pathways [11-13]. Situ et al. reveal that MUC1 is overexpressed in 86.3\% adenocarcinomas, $39.1 \%$ squamous cell carcinomas, and $74.1 \%$ other NSCLC subtypes, and acts as an independent prognostic factor of NSCLC [14, 15]. MUC4 is upregulated in patients with lung adenocarcinoma (LUAD) at stages I (138 cases) and II (17 cases), and its high levels in early-stage patients are correlated with an unfavorable prognosis [16]. In addition, MUC5AC is elevated in $26.2 \%(16 / 61)$ patients with stage I/II NSCLC and predicts the poor clinicopathological profiles and prognosis [17]. These studies suggest a close correlation between mucins and lung cancer pathogenesis, development, and prognosis.

MUC3A is membrane-associated mucin with glycosylation and expressed in various epithelial cells. MUC3A contains a sperm protein, enterokinase, agrin, and epithelial growth factor (EGF) domain and functions through ligand binding and intracellular signalling pathways [18]. Favorably, MUC3A is rarely expressed in normal pulmonary epithelial cells, making it been a promising tumor biomarker for lung cancer [19]. Moreover, MUC3A exerted oncogenic profiles in breast, pancreatic, gastric, colorectal, prostate, and renal cancers [20-25].

Currently, the mechanism of MUCs' effects on the occurrence and development of NSCLC is still unclear as to the complex biological properties of mucins in a cell type-specific manner [25]. In this study, we report that MUC3A exerts oncogenic profiles in NSCLC and may be a promising marker to predict radiotherapeutic effectiveness. The development of a monoclonal antibody targeting MUC3A should be encouraging for fighting against NSCLC.

\section{Material and Methods}

\section{Tissue microarray and bioinformatics analysis}

The lung cancer tissue microarray, containing 92 LUAD tissues and paired para-carcinoma tissues, was purchased from Outdo (Shanghai, China). The samples come from the National Human Genetic Resources Sharing Service Platform (2005DKA21300). All the dots on the chip were detected by immuno- histochemistry (IHC) with survival information and included in univariate and multivariate survival analyses. Both the intensity and positive percentages of immunohistochemistry (IHC) were used to examine the MUC3A expression: the IHC H-score (values $0-400)=$ the scores for intensity of positive staining (less than $5 \%$ scored " 0 "; $5-24 \%$ scored " 1 "; $25-49 \%$ scored " 2 "; $50-74 \%$ scored " 3 "; and more than $74 \%$ scored " 4 ") $\times$ the percentage of positive-stained cells $\times 100$. In the cancer tissues of all the 92 cases, the median MUC3A H-score was 140. Oncomine, Km plotter, and Gepia were used for bioinformatic analysis.

\section{Cells}

The H1975, A549, H1299, HCC827, H460, and PC9 cells were purchased from the Type Culture Collection (Chinese Academy of Sciences, Shanghai, China) with the short tandem repeat sequencing authentication (Cellcook Biotech, Guangzhou, China, Figure S1-2). Cells were cultured in RPMI-1640 medium (HyClone, USA) with $10 \%$ fetal bovine serum (Gibco, Cat\#: A4766801, USA), 100 units/ml penicillin and $100 \mu \mathrm{g} / \mathrm{ml}$ streptomycin (HyClone).

\section{Cell proliferation assay}

The cells were seeded in 96-well plates $(1,000$ cells/well) and cultured for 5 days. After adding $10 \mu \mathrm{l}$ CCK-8 (Dojindo, Japan) to each well and incubating at $37^{\circ} \mathrm{C}$ for $2 \mathrm{~h}$, the absorbance at $450 \mathrm{~nm}$ was measured by the Rayto-6000 system (Rayto, China) and normalized to that of RPMI-1640 medium as control.

\section{Colony formation assay}

For cell proliferation, we seeded 50 cells to each well of 12-well plates for 7 days, then fixed with $4 \%$ paraformaldehyde (PFA) and stained with crystal violet.

For radiation sensitivity, 100, 200, 400, 1,000, 2,000 and 10,000 cells were seeded in 6-well plates. The cells were then irradiated at $0,1,2,4,6,8$, and 10 Gy with the Small Animal Radiation Research Platform (SARRP, 204 kV, PXI X-RAD 225Cx, CT, USA). After 15 days, the colonies were fixed with $4 \%$ PFA for $15 \mathrm{~min}$ and stained with crystal violet. The cells were photographed, and the numbers of colonies were counted. A "multitarget-single hitting" model was applied to fit the survival curve.

\section{Cell cycle assay}

After starving for $6 \mathrm{~h}$, the cells were harvested, then fixed with cold ethanol overnight. After totally removed ethanol, cells were incubated with propidium iodide and RNAse (BD, USA) in the dark for $15 \mathrm{~min}$. The stained cells were assessed by flow cytometry (FACS AriaIII, BD, USA) and analyzed by FlowJo vX.0.7 software. 


\section{Cell apoptosis assay}

The cells cultured on 24-mm coverslips were fixed by $4 \%$ PFA at room temperature for $30 \mathrm{~min}$. After incubating with $0.1 \%$ Triton X-100 for $2 \mathrm{~min}$, the TUNEL assay was performed according to the manufacturer's instruction (Roche, Germany). The nuclei were labeled with DAPI at $2 \mu \mathrm{g} / \mathrm{ml}$, then analyzed by a fluorescence microscope (Olympus IX 73 DP80, Japan).

\section{Modified Boyden chamber migration and invasion assay}

The cells were seeded into the upper chambers of 12-well plates $\left(1.5 \times 10^{5}\right.$ cells / well $)$ and cultured for 24 $\mathrm{h}$. For invasion assay, the transwell membranes were precoated with Matrigel (1:40 dilution, Corning, USA) at $37^{\circ} \mathrm{C}$. After $24 \mathrm{~h}$, the cells were fixed with $4 \%$ PFA and stained with $0.1 \%$ crystal violet. The invaded and migrated cells were counted at 5 random fields per chamber under a phase-contrast microscope (DC 300F, Leica, Germany).

\section{Protein and cytoplasmitc protein extraction}

The nuclear and cytoplasmic components were extracted using the NE-PER Nuclear Cytoplasmic Extraction Reagent kit (Pierce, Rockford, IL, USA). Briefly, the treated cells were washed twice with cold PBS, and centrifuged at $1000 \mathrm{rpm}$ for $5 \mathrm{~min}$. The cell pellet was suspended in $200 \mu \mathrm{l}$ of the cytoplasmic extraction reagent I by vortexing for $5 \mathrm{~s}$. The suspension was incubated on ice for $20 \mathrm{~min}$ followed by the addition of $11 \mu \mathrm{l}$ of the second cytoplasmic extraction reagent II, vortexed for $5 \mathrm{~s}$, incubated on ice for $1 \mathrm{~min}$ and centrifuged at 12,000 $\mathrm{g}$ for $5 \mathrm{~min}$. The supernatant fraction (cytoplasmic extract) was collected. The insoluble pellet fraction, which contains crude nuclei, was resuspended in $100 \mu$ of nuclear extraction reagent by vortexing for $15 \mathrm{~s}$ and incubated on ice for $10 \mathrm{~min}$, then centrifuged at $12,000 \mathrm{~g}$ for 10 min. The resulting supernatant, constituting the nuclear extract, was used for the subsequent experiments.

\section{Immunoblotting}

The cells were lysed in RIPA buffer containing protease inhibitor and phosphatase inhibitor (SigmaAldrich, USA) on ice for $30 \mathrm{~min}$. The cell lysates were centrifuged at $12,000 \mathrm{~g}$ for $15 \mathrm{~min}$, and the supernatants were collected. Co-immunoprecipitation was performed as the protocol of the BeaverBeads ${ }^{\mathrm{TM}}$ Protein A/G Kit (Beaverbio, Suzhou, China). The total proteins were separated using 7.5-12.5\% SDS-PAGE (Bio-Rad) and transferred to a PVDF membrane (Millipore, USA). TBST with 5\% milk was used to block non-specific binding sites. The dilution of antibodies for WB has been list in Table S1-2. The immunoreactive proteins were detected by enhanced chemiluminescence (Thermo Fisher, USA).

\section{Immunofluorescence}

The NSCLC cells were seeded on 24-mm coverslips, fixed with $4 \%$ PFA for 30 min, penetrated with $0.1 \%$ Triton X-100 and blocked with $5 \%$ bovine serum albumin at room temperature for $1 \mathrm{~h}$. After incubated with primary antibodies at $4{ }^{\circ} \mathrm{C}$ overnight, the cells were incubated with $\mathrm{Cy}$ 3-labelled or FITC-labelled secondary antibodies at room temperature for $1 \mathrm{~h}$. The nuclei were labeled with DAPI $(2 \mu \mathrm{g} / \mathrm{ml})$. The immunofluorescent staining was examined using a fluorescent microscope (IX 73 DP80, Olympus, Japan) or a laser confocal microscope (C2, Nikon, Japan). The mean density was applied to semi-qualified by Image-Pro Plus 6.0.

\section{Mcherry-GFP-LC3 II autophagy assay}

Cells $\left(3 \times 10^{5}\right)$ were seeded in a 6-well plate and transfected with mCherry-GFP-LC3 II (Beyotime Ltd, Beijing, China) adenovirus. The cells were irradiated 4 Gy X-rays $24 \mathrm{~h}$ after infection. A fluorescent microscope (Olympus IX 73 DP80, Japan) was used to observe the fluorescence $12 \mathrm{~h}$ after irradiation. After the cells were infected with Ad-mCherry-GFP-LC3B adenovirus, mCherry-GFP-LC3B existed in the cytoplasm in the form of diffuse yellow fluorescence (the combined effect of mCherry and GFP), while in the case of autophagy, mCherry-GFP-LC3B gathered on the autophagy membrane in the form of yellow spots (LC3B dot or punctae)). When autophagosomes fuse with lysosomes, they appear in the form of red spots due to the partial quenching of GFP fluorescence.

\section{Transmission electron microscopy (TEM)}

Four hours after irradiation, the cells were washed 3 times with PBS, and collected by a cell scraper. Then, cell suspensions were centrifuged at $2000 \mathrm{r} / \mathrm{min}$ for $5 \mathrm{~min}$, and the supernatants were discarded. The cell pellets were fixed with $2.5 \%$ glutaraldehyde for $1 \mathrm{~h}$, and then fixed with $1 \%$ osmium tetroxide buffer for $1 \mathrm{~h}$. Subsequently, an ascending series of alcohol were performed for dehydration before embedding samples in Araldite. Ultrathin sections were observed with TEM (HT7700, Hitachi, Japan, 100kV).

\section{Animals}

Six-week-old female BALB-C/null mice (Vital River Laboratory Animal Technology Co., Ltd, Beijing, China) were housed in a specific pathogen-free, temperature, and humidity-controlled environment. According to the Wuhan University 
Animal Care Facility and the National Institutes of Health Guidelines, all animal experiments were performed.

\section{Xenograft tumor model}

Approximately $5 \times 10^{6}$ H1975-GFP cells were harvested, resuspended in $100 \mu \mathrm{l}$ PBS, and injected subcutaneously into each mouse's right flank. Treatment was commenced when the tumor size reached approximately $100 \mathrm{~mm}^{3}$. The size of the tumor and the weight of the mice were recorded every day. An animal in vivo imaging system was used to evaluate the tumor's size on Days 7 and 14 after radiotherapy. Tumor volume $(\mathrm{V})$ was calculated according to the formula: $\Pi / 6 \times$ length $\times$ width $^{2}$.

The tissues from the tumor-bearing mice were fixed in $4 \%$ PFA at $4{ }^{\circ} \mathrm{C}$ overnight and embedded into paraffin (Paraplast, Sigma-Aldrich) using a tissue processor (Thermo Fisher Scientific, Loughborough, UK). Paraffin sections $(5 \mu \mathrm{m})$ were cut with a rotation microtome (Thermo Fisher Scientific, Bremen, Germany). The images were collected by Versa 8 (Leica, Germany). The integrated optical density of IHC sections was calculated by Image-Pro Plus 6.0.

\section{Results}

The poor survival in lung cancer is associated with the high expression of MUC3A

From the public database, we found that MUC3A levels in LUAD and squamous cell carcinoma were significantly higher than those in normal lung tissues $(p<0.01$, Figure S3A). We performed a LUAD tissue microarray (Figure S3B) with a particular scoring system (Figure 1A). Demographic characteristics and pathological baseline of tissue-chip were listed in Table 1, showing that the MUC3A was significantly elevated in LUAD tissues ( $p<0.001$, Figure 1B). Samples were split into 2 groups by the best cut-off value at $\mathrm{H}$-score 140, and MUC3A was positively associated with advanced pathological stages (Figure 1C) and differentiation (Figure 1D). Moreover, high MUC3A expression levels predicted shorter survival in both tissue-chip (median survival 47.5 versus 54.5 months, $p=0.045$, Figure 1E) and public database (http:/ / kmplot.com, p $=0.00051$, Figure 1F). Surprisingly, tumor size and lymphatic metastasis status failed to correlate with MUC3A expression levels (Figure S3C, D).

\section{Statistical analyses}

Each experiment was performed in triplicates, and data presented in the representation of 3 individual experiments. A two-tailed Student's t-test and one-way analysis of variance (ANOVA) were used to evaluate different groups' statistical significance. Statistical analyses were performed with SPSS 16.0. $P<0.05$ were considered as statistical significance.

Table 1. MUC3A expression and demographic and clinicopathological characteristics

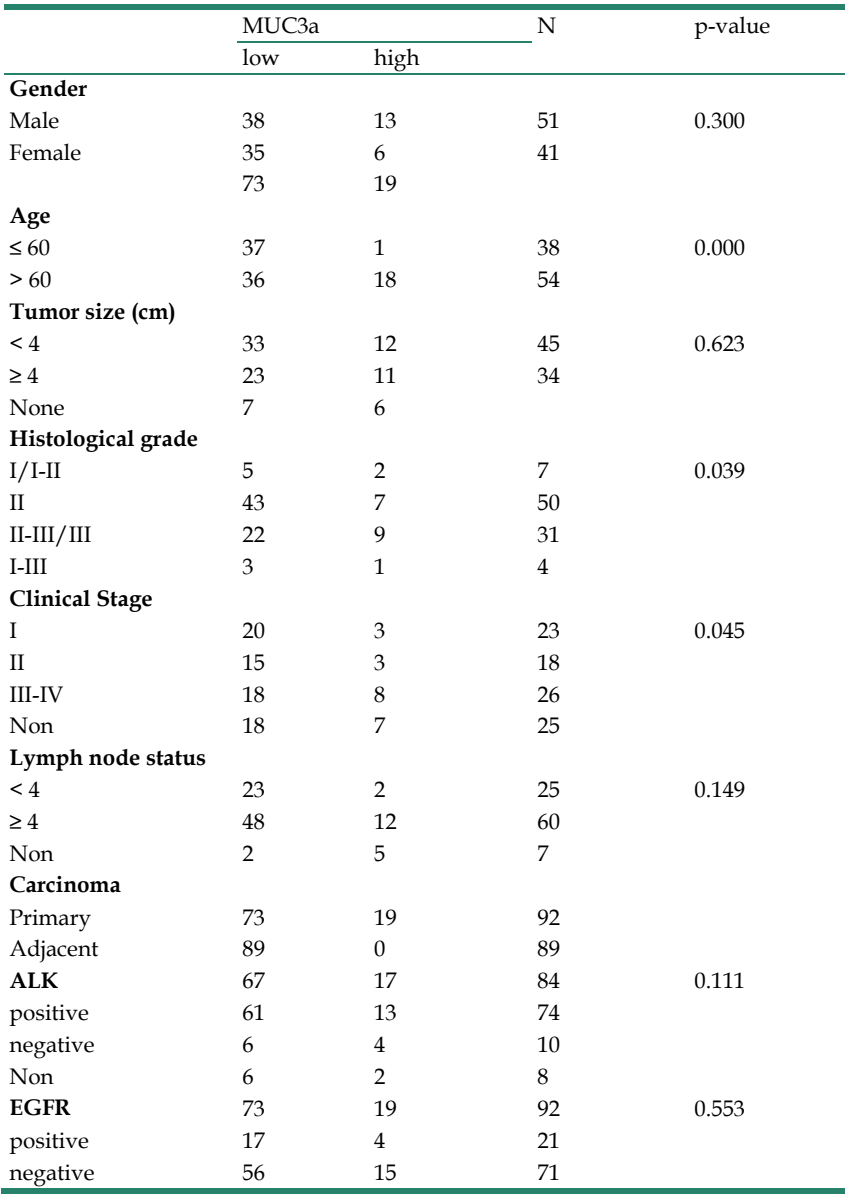

We further verified the expression of MUC3A in 6 human NSCLC cell lines, including H1975, A549, H1299, HCC827, H460, and PC9. Among these cell lines, LUAD, H1975 and H1299 cells we observed to be expressing high amount of MUC3A and therefore, we have used these two cells line for our further exploration.

\section{MUC3A knockdown attenuated NSCLC cell proliferation, migration, and invasion}

Lentiviruses carrying MUC3A shRNAs were used to obtain MUC3A-knockdown H1975 and H1299 cells (Figure 2A, B). The ability of colony formation was notably impaired after knockdown of MUC3A gene (Figure 2C). Interestingly, the Ki-67 index and CCK-8 assay indicated that MUC3A knockdown remarkably attenuated the cell proliferation (Figure 2D, E). We further investigated the cell cycle attribution and found that MUC3A knockdown caused the cells arrested at the G1/S phase with the 
depletion of Cyclin D1, CDK4, and CDK6 (Figure 2F, G).

In addition, impaired function of MUC3A abrogated cell migration (Figure $2 \mathrm{H}$ ) with decreased expression of MMP-2 and MMP-9 (Figure 2I, J).
However, the size and shape of NSCLC cells, as well as proteins involved in epithelial-to-mesenchymal transition were not changed after MUC3A knockdown (Figure 2I, J).

A

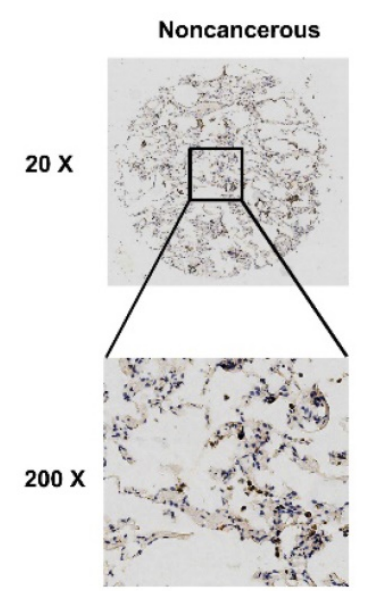

B

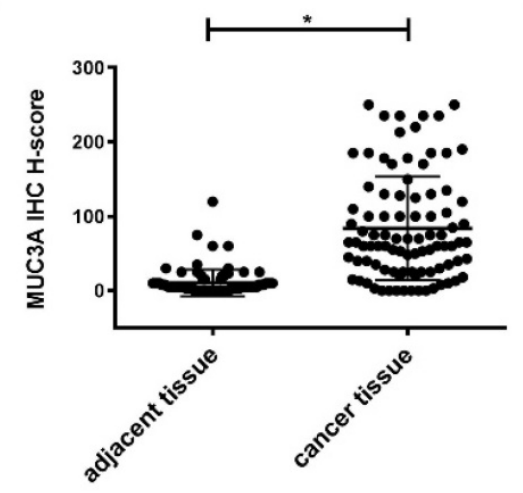

Lung cancer

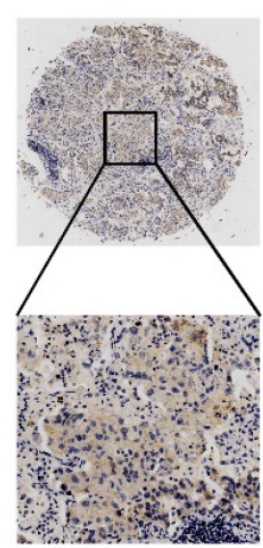

1 score

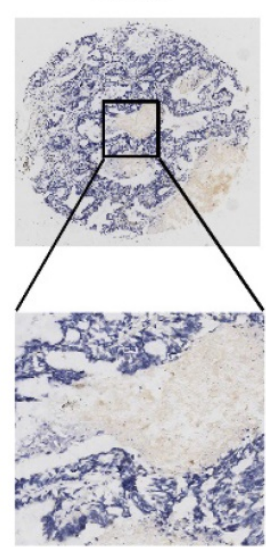

2 score

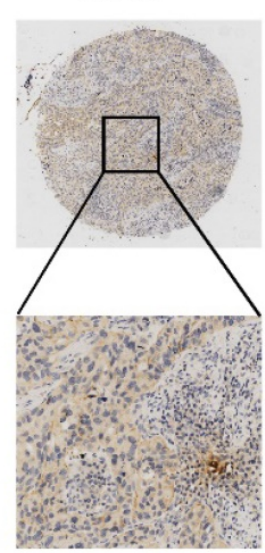

3 score

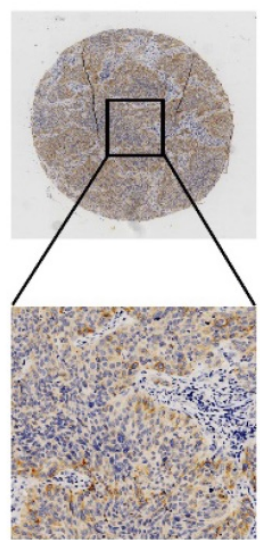

C

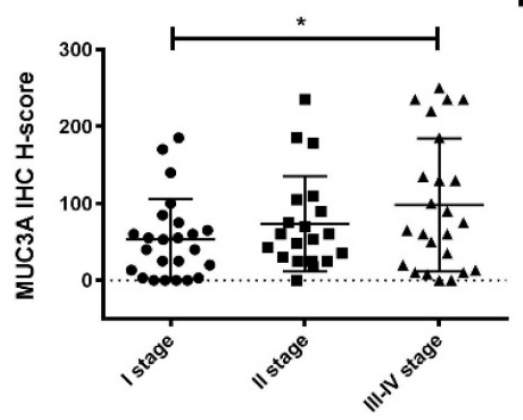

D

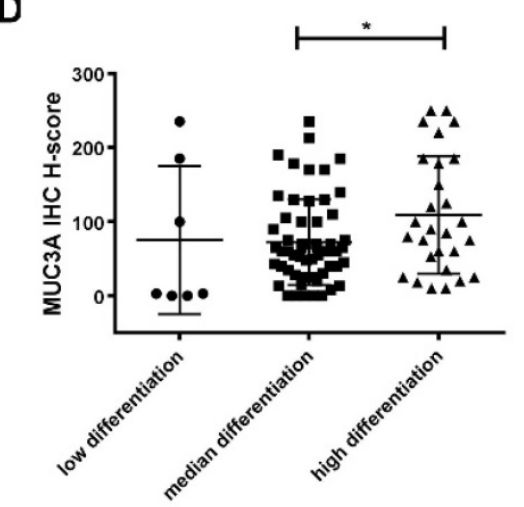

E

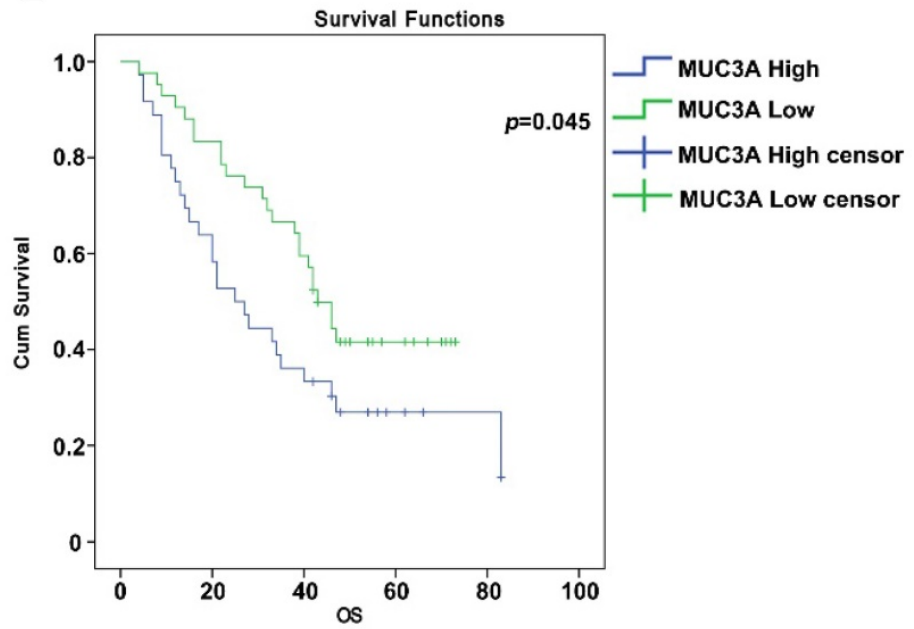

$\mathbf{F}$

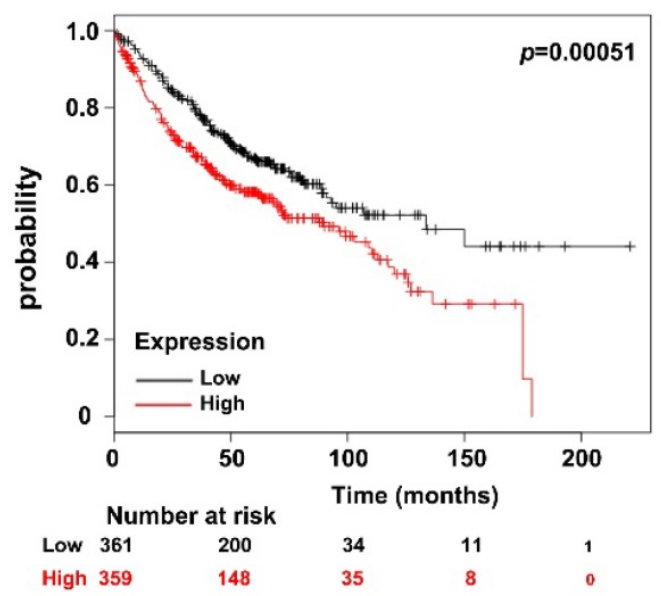

Figure 1. MUC3A was highly expressed in lung cancer and relevant to the poor survival in database and tissue microarray. (A) The $20 \times$ and $200 \times$ representative images of IHC. (B) The expression levels of MUC3A protein were significantly higher in NSCLC tissues than those in the paired normal tissues. The tissue microarray results included 92 pairs ( $P<0.001$, paired t-test). (C) MUC3A expression levels in lung cancer tissues subgrouped by staging ( $<<0.001, A N O V A)$. (D) MUC3A expression levels in lung cancer tissues subgrouped by differentiation ( $\mathrm{P}<0.001$, ANOVA). (E) Kaplan-Meier plot of 92 patients with survival data (from tissue arrays) stratified by MUC3A expression levels. Patients expressing less MUC3A displayed higher overall survival than the other patients ( $\mathrm{P}=0.045, \mathrm{Kaplan}-\mathrm{Meier}$ survival test). ( $\mathrm{F}$ ) Kaplan-Meier plot of 720 patients with survival data stratified by MUC3A mRNA levels. Patients expressing more MUC3A displayed shorter overall survival than the other patients ( $\mathrm{P}=$ 0.00051 , Kaplan-Meier survival test). 
A

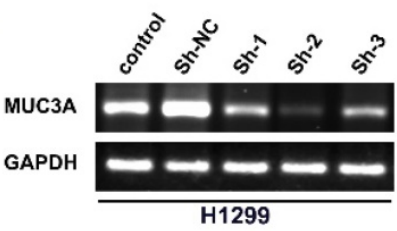

C
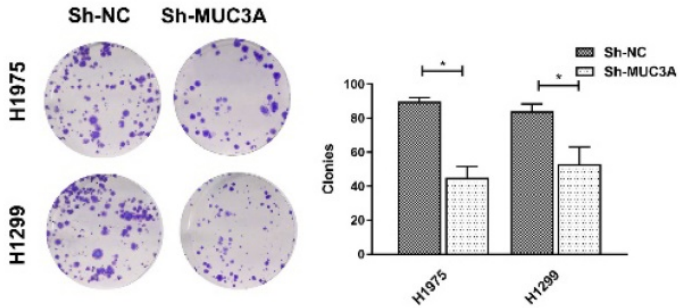

E
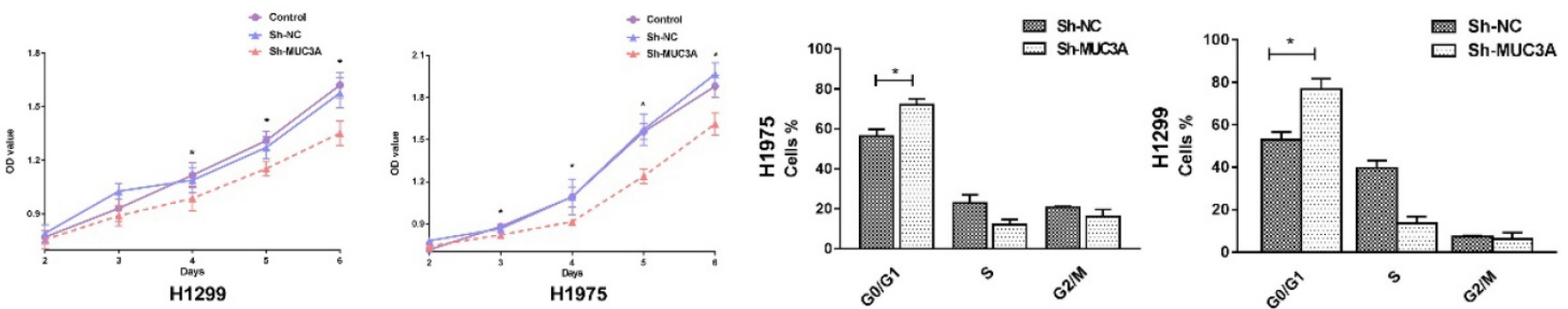

G

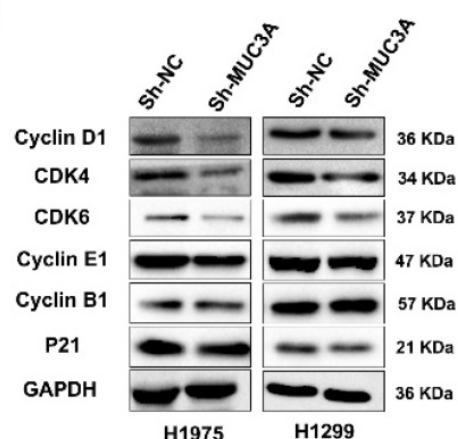

H
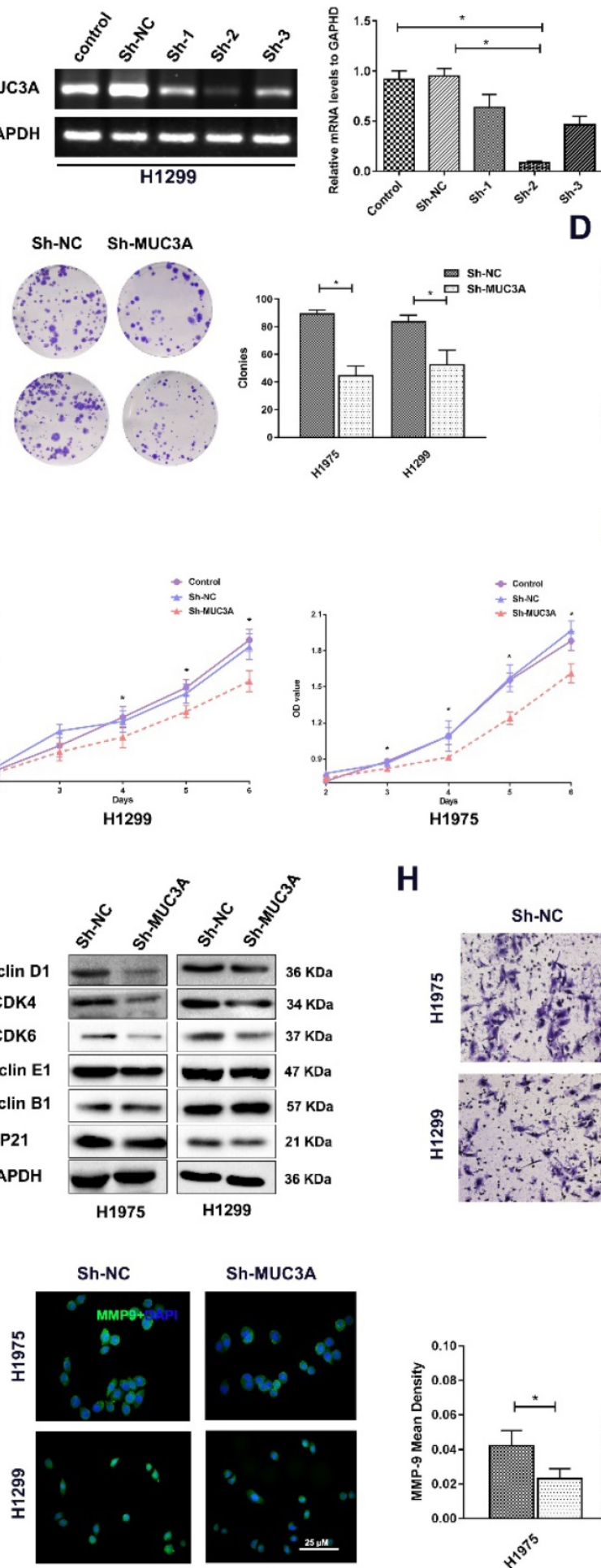

D
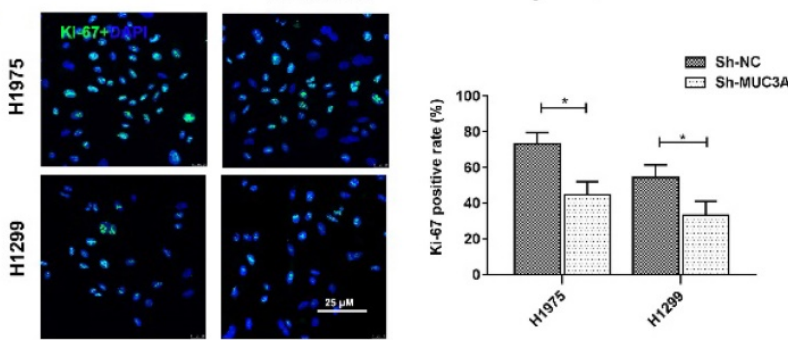

F

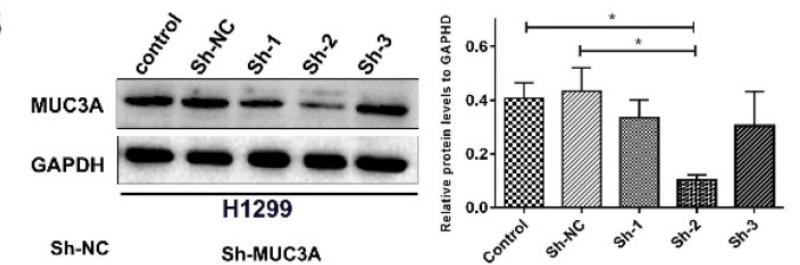

F
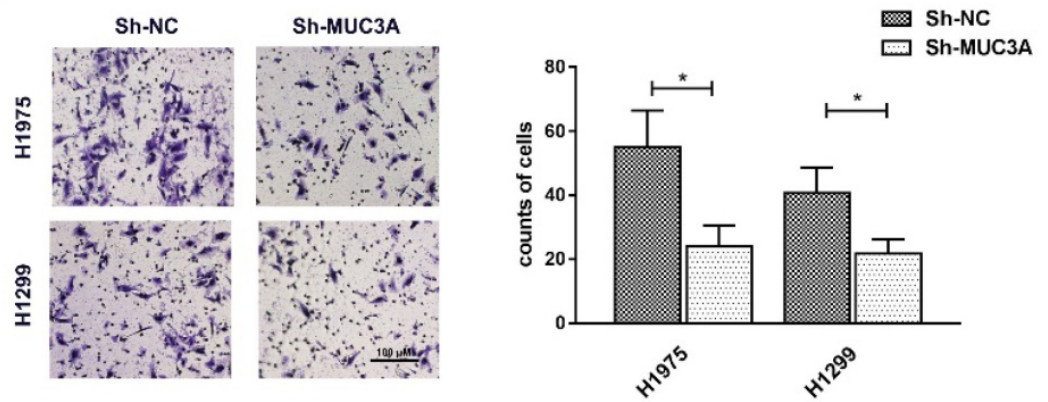

J

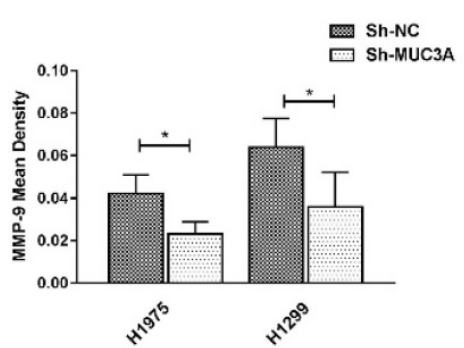

Figure 2. MUC3A knockdown attenuated NSCLC cell proliferation, migration, and invasion. (A) PCR analysis to detect the knockdown effects of different shRNAs. shRNA-2 was more efficient than the others in H1299 cells. (B) WB analysis to detect the knockdown effects of different shRNAs in H1299 cells. (C) Representative images of crystal violet stain on Day 15. (D) Representative images of Ki-67 IF staining in H1975 and H1299 cells. (E) CCK-8 array to detect cell proliferation. (F) FACS analysis to detect the cell cycle distribution. More cells in the MUC3A knockdown group were accumulated at G0/G1. (G) Immunoblotting analysis of protein abundance of Cyclin D1, CDK4, CDK6, Cyclin E1, Cyclin B1, p21. (H) Transwell assay for cell migration and invasion. The MUC3A knockdown group had significantly fewer migration and invasion cells than the control group. (I) Representative images of MMP9 IF staining in $\mathrm{H} 1975$ and $\mathrm{H} 1299$ cells. MUC3A knockdown reduced MMP9 expression. (J) Western blotting analysis of protein abundance of ICAMI, MMP2, MMP9, E-cadherin, Vimentin, and N-cadherin. *, $\mathrm{p}<0.05$.

\section{MUC3A knockdown inhibited the activity of the NFKB pathway}

We utilized the GEPIA online tool and found that there was no correlation between the MUC3A and P65 (Figure 3A). We confirmed that MUC3A knockdown could not affect the P65 expression in whole-cell lysis (Figure 3B). However, the protein- 
protein interaction database indicated that P65 could interfere with MUC3A based on a high-throughput affinity chromatography analysis. We further confirmed the physical interaction between P65 and MUC3A in H1299 and H1975 cells via co-immunoprecipitation (Figure 3C).

Continuously, we found there was only a slightly higher ratio of cytoplasm and nucleus P65 expression in MUC3A knockdown cells. However, once the cells were treated with a P65 activator, tumor necrosis factor $\alpha$ (TNF- $\alpha$ ), at $10 \mathrm{ng} / \mathrm{ml}$ for $30 \mathrm{~min}, \mathrm{P} 65$ was rapidly phosphorylated and attenuated in both nuclei and cytoplasm of MUC3A-knockdown cells. Furthermore, a very low amount of IкB was accumulated in MUA3A-knockdown cells even after TNF- $\alpha$ stimulation (Figure 3D). Favorably, we obtained the same findings via immunofluorescence and semi-qualified by laser confocal microscopy (Figure 3E). The IкB and P65 laser scatter plots were linearly formed in MUC3A knockdown cells (Figure $3 \mathrm{~F})$, indicating a colocalization for IKB and P65.
Moreover, there was a weak binding observed between IкB and P65 in MUC3A-knockdown cells, suggesting that the NFKB pathway was attenuated by MUC3A (Figure S4A-C).

\section{MUC3A knockdown contributed to a severe DNA damages induction upon the exposure of X-rays}

Previously, siRNA screening reported that MUC3A silencing would elevate the cellular level of $\mathrm{Y}$-H2AX. [26]. Both MUC3A-wild type and knockdown cells were irradiated with 2 Gy X-rays and then fixed for $30 \mathrm{~min}$. As a result, we observed that MUC3A knockdown cells induced more DNA damages and promoted radiation effects more significant than those of the wild type cells (Figure $4 \mathrm{~A}-\mathrm{C})$. We further verified our results by TUNEL assay, however, here we have used $10 \mathrm{~Gy}$ X-rays to irradiate the cells to cope up with sensitivity limitations of the TUNEL assay. The TUNEL results confirmed the synergistic effects of MUC3A
A

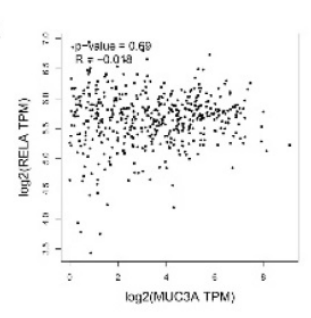

B

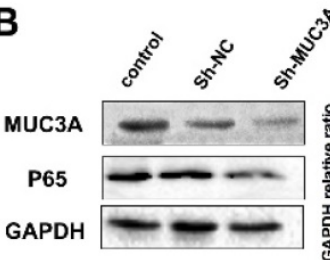

D

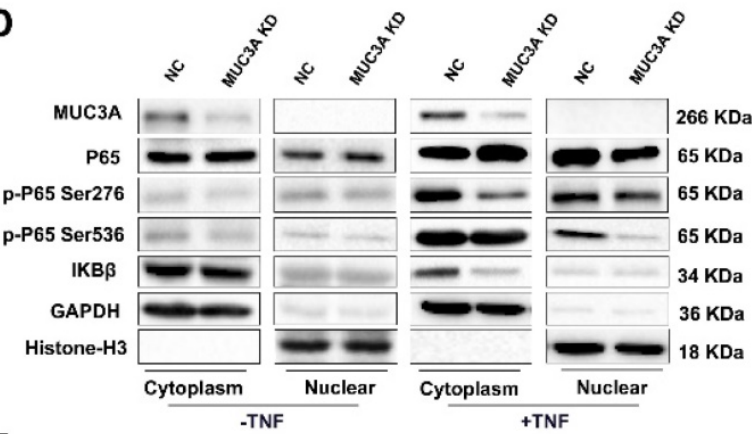

E
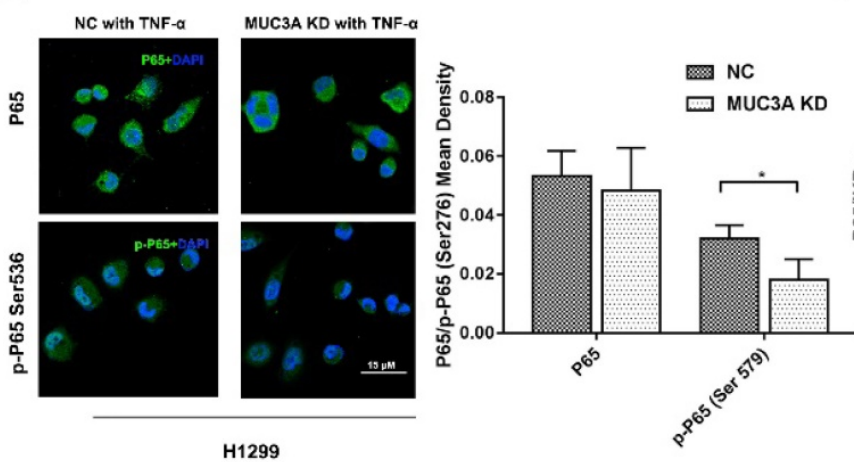

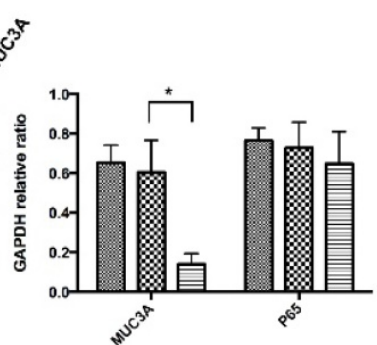

C

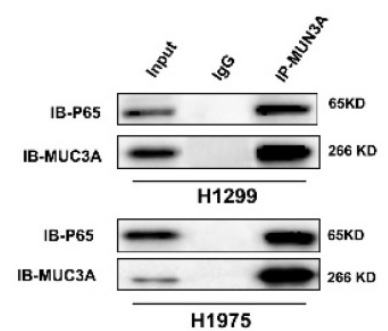

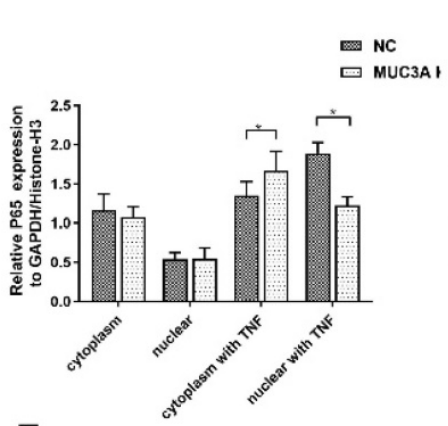

$\mathbf{F}$

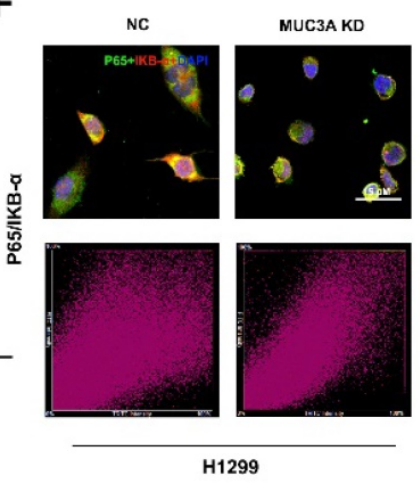

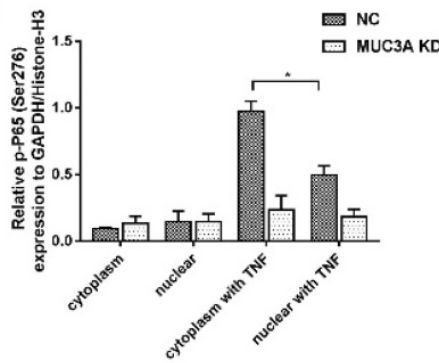

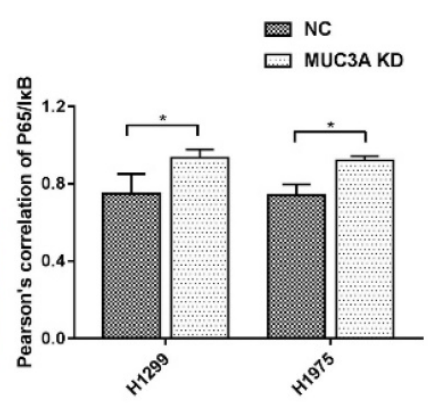

Figure 3. MUC3A knockdown reduced the activity of the NF-KB pathway. $(A)$ Pearson correlation between $M U C 3 A$ and $P 65$ log 2 expression. $P=0.69, R=-0.018$. $(B)$ WB to detect the relationship between MUC3A and p65. (C) Co-IP to analyze the binding of MUC3A and p65. The representative images exhibited that MUC3A was linked to p65. (D) WB was used to investigate the MUC3A, p65, p-p65, IKB, GAPDH, and Histone H3. (E) Representative images of p65 and p-p65 IF staining in H1299 cells. (F) IF to detect the binding condition of $\mathrm{p} 65$ (green) and IKB (red). The scatter image presented the correlation of fluorescence intensity between FITC and TRITC. *, P < 0.05 . 
knockdown and irradiation on DNA damage (Figure 4D). The survival curve indicated that MUC3A-knockdown cells were more radiosensitive than those of the wild type (Figure 4E-F). Moreover, immunoblotting results showed that MUC3Aknockdown cells exposed to 2 Gy X-rays had increased BAX expression levels and cleaved-PARP, indicating an elevation in cell death (Figure 4G).

Higher expression levels of $\mathrm{y}-\mathrm{H} 2 \mathrm{AX}, \mathrm{p}-\mathrm{ATM}$, and p-ATR were observed in MUC3A-knockdown cells after 2 Gy irradiation (Figure 5A). In addition, the BRCA1 and RAD51 repair axis was blocked in MUC3A-knockdown cell along with the suppression of XRCC6 in MUC3A-knockdown cells after irradiation. Also, HIF-1a, p-P65, and p-P53 were decreased in MUC3A-knockdown cells after 2 Gy irradiation suggesting a severe DNA damage in MUC3A-knockdown cell.

A
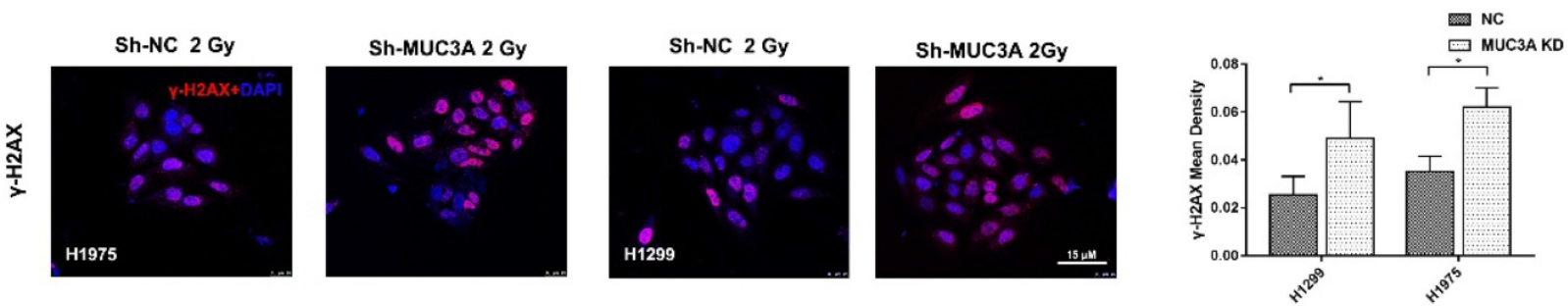

B
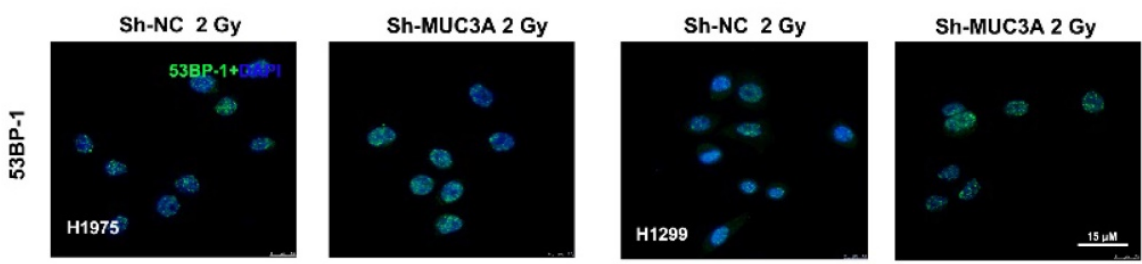

C
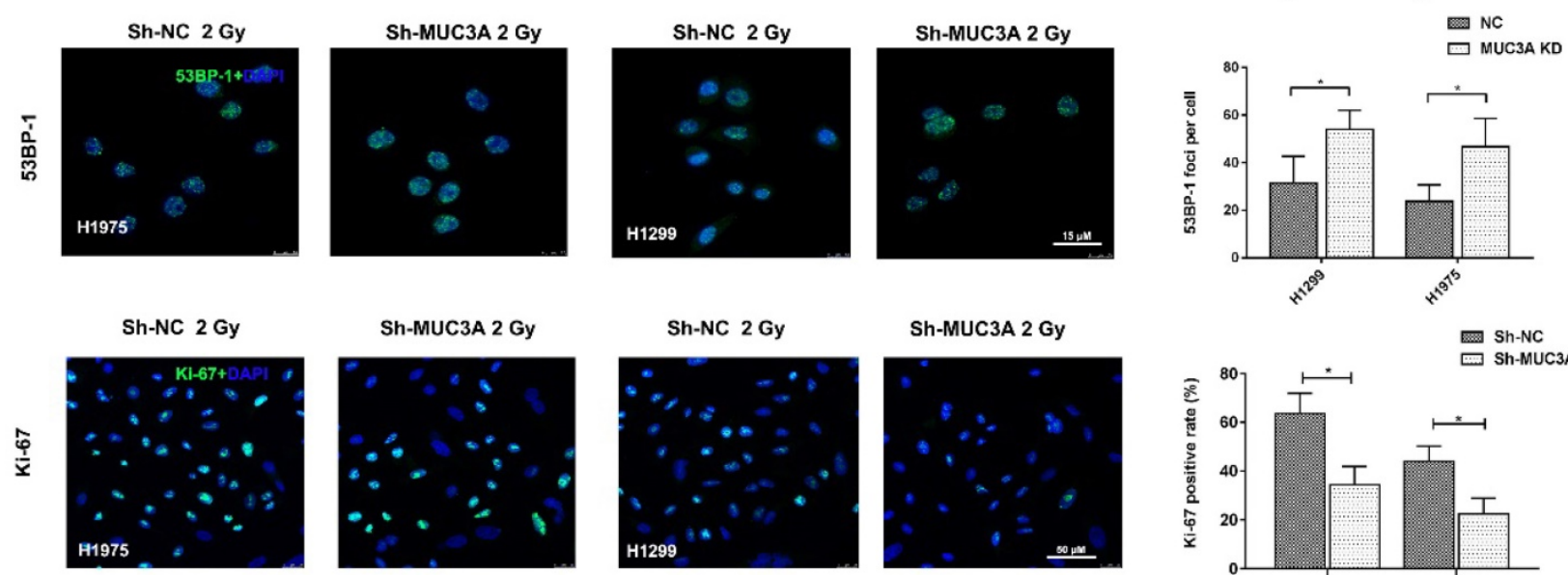

D
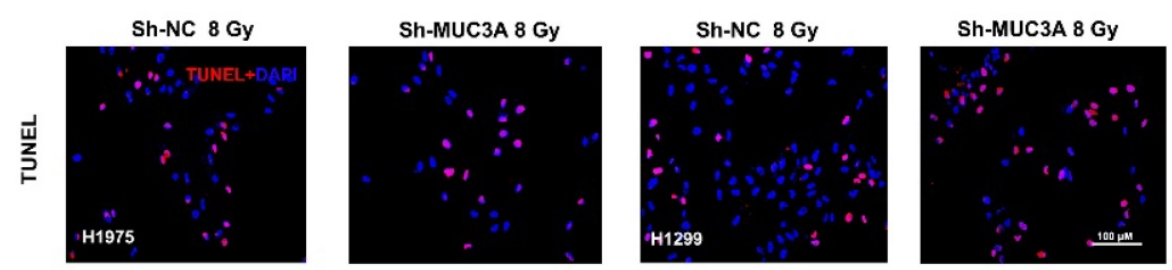

E

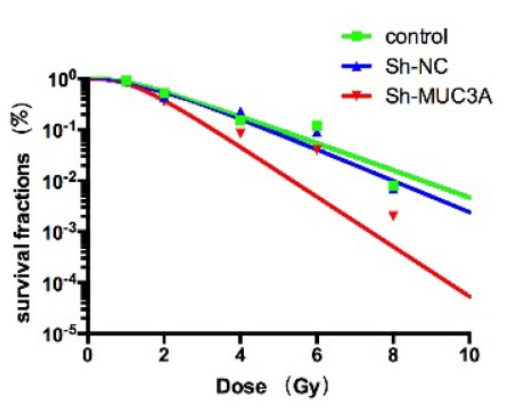

$\mathbf{F}$

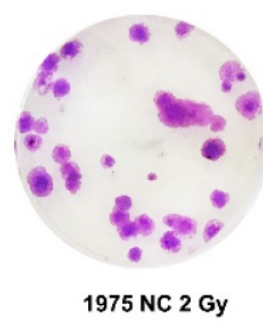

G
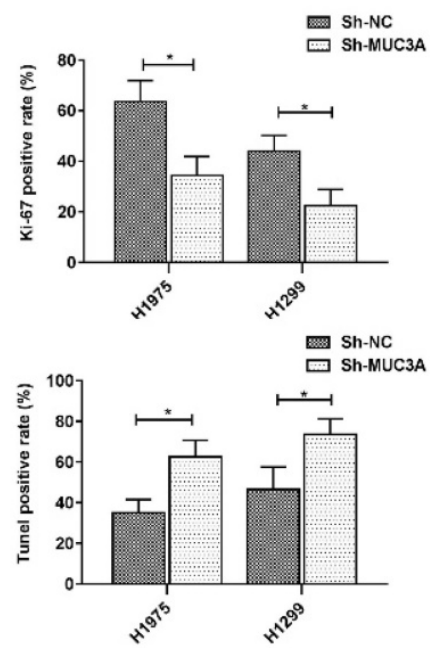

Figure 4. MUC3A knockdown induced more DNA damages by X-rays. (A) Representative images of $\mathrm{Y}-\mathrm{H} 2 \mathrm{AX}$ IF staining in $\mathrm{H} 1975$ and $\mathrm{H} 1299$ cells. (B) Representative images of 53BPI IF staining in H1975 and H1299 cells. (C) Representative images of Ki67 IF staining in H1975 and H1299 cells. (D) Representative images of TUNEL staining in $\mathrm{H} 1975$ and $\mathrm{H} 1299$ cells. (E) The multitarget-single-hitting model was used to fit the survival curve. The survival fraction of MUC3A knockdown cells was significantly lower than that of the control groups. (F) Representative crystal violet staining photos of H1975 parental and MUC3A knockdown cells with 2 Gy irradiation. (G) Western blotting analysis of BLC2, BAX, and PARP protein levels. *, $\mathrm{p}<0.05$. 
A

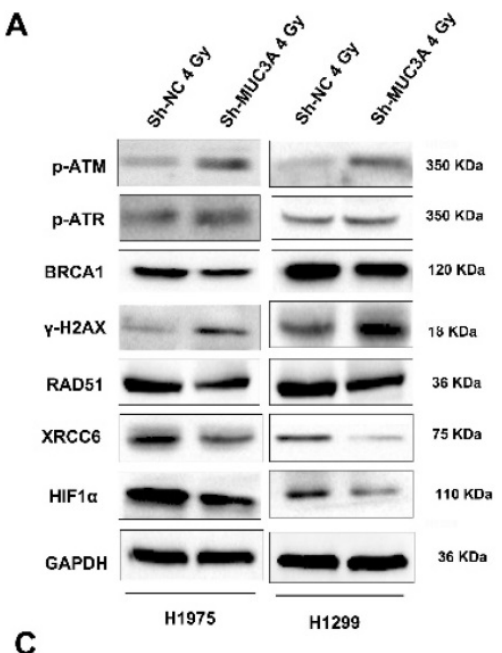

C

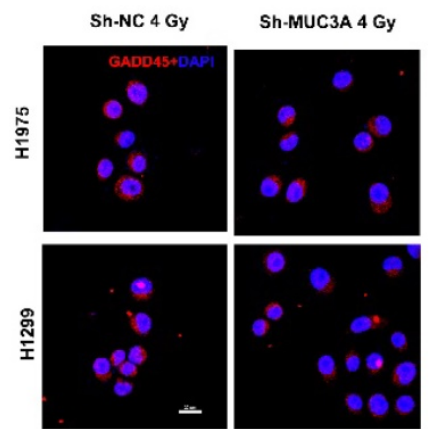

B
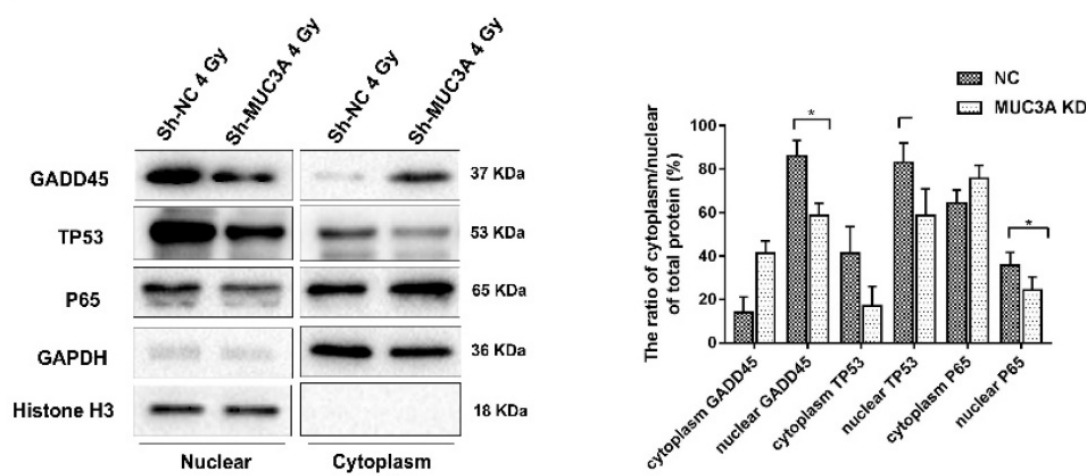

D

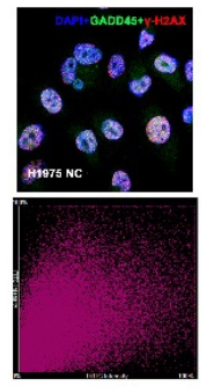

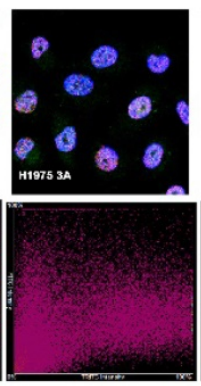

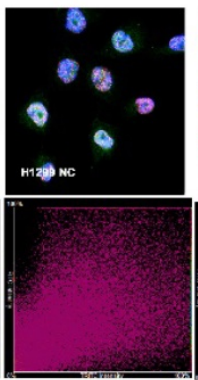

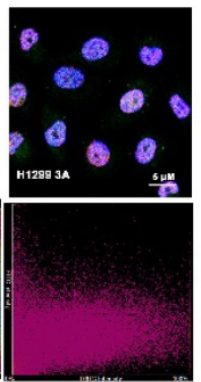

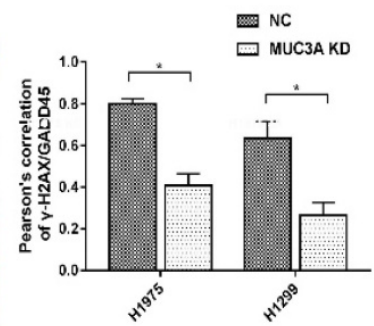

Figure 5. The mechanism of MUC3A knockdown induced more DNA damages by X-rays. (A) Immunoblotting analysis of p-ATM, p-ATR, $Y-H 2 A X, B R C A 1, R A D 51$, XCRR6, and HIFla protein levels after 4 Gy irradiation. (B) Immunoblotting analysis to investigate the plasm and nucleus protein levels of GADD45, TP53, and p65. (C) Representative images of GADD45 in $\mathrm{H} 1975$ and $\mathrm{H} 1299$ cells after 4 Gy irradiation. (D) As previously described, specific software was used to analyze the co-localization of $\mathrm{Y}-\mathrm{H} 2 \mathrm{AX}$ and DADD45. In MUC3A-knockdown cells, less GADD45 was recruited to $\mathrm{Y}-\mathrm{H} 2 \mathrm{AX}$. *, $\mathrm{P}<0.05$.

Additionally, we investigated the transcriptional regulators and their localization including S5A, P65, P53, and GADD45 and found that these proteins were decreased in the nucleus after losing the function of MUC3A (Figure 5B) suggesting that the MUC3A has a key role in translocation of these marker from cytosol to nucleus. On the other hand, RAD51 and XRCC6 were observed to be located in the nucleus in wild type cells and were absent in the nucleus of MUC3A-knockdown cells (Figure S5B, C). Interestingly, MUC3A knockdown impaired GADD45 nucleus translocation (Figure 5C) with less binding with $\gamma-\mathrm{H} 2 \mathrm{AX}$, indicating less DNA damage repair activities initiated in the MUC3A-knockdown cells after irradiation (Figure 5D).

Additionally, the exposure of 4 Gy irradiation to the MUC3A knockdown cells induced the late stage of autophagy as evident by the accumulation of red dots (Figure S5D). Similarly, immunoblotting results also showed higher LC3 II and lower P62 protein levels (Figure S5E) along with the accumulation of significantly higher autophagic vacuole in MUC3A-knockdown cells after irradiation (Figure S5F). Unfortunately, our results were unable to support that MUC3A facilitated radio sensitivity via affecting cellular autophagy as Beclin-1 and ATG-5 did not accumulate in MUC3A-knockdown cells.

\section{MUC3A knockdown impaired tumor growth and promoted radiosensitivity in vivo}

BALB-c/Null mice were subcutaneously implanted with H1975-NC-GFP or H1975-MUC3A KD-GFP cells in the right flank (Figure 6A). Approximately 2 weeks after implantation, the tumor size reached $150 \mathrm{~mm}^{3}$, and at this time point the mice received radiation or mock treatment. MUC3A knockdown significantly suppressed tumor volume. The combination of radiation exerted synergistic effects on tumor reduction at both Days 7 and 14 post-treatment (Figure 6B-F). All the masses were identified as malignant tumors via $\mathrm{HE}$ staining (Figure 6G).

Favorably, MUC3A knockdown and X-rays exerted significantly synergetic effects in vivo (Figure 7A, B). The verification of knock down of MUC3A gene via shRNA lentivirus infection was done by IHC (Figure 7C). Similar to the findings in vitro, MMP-2 was notably decreased in the MUC3A-knockdown tumor (Figure 7D). HIF-1a and VEGF expression levels were attenuated in MUC3A-knockdown tumors after irradiation (Figure 7E-F). 


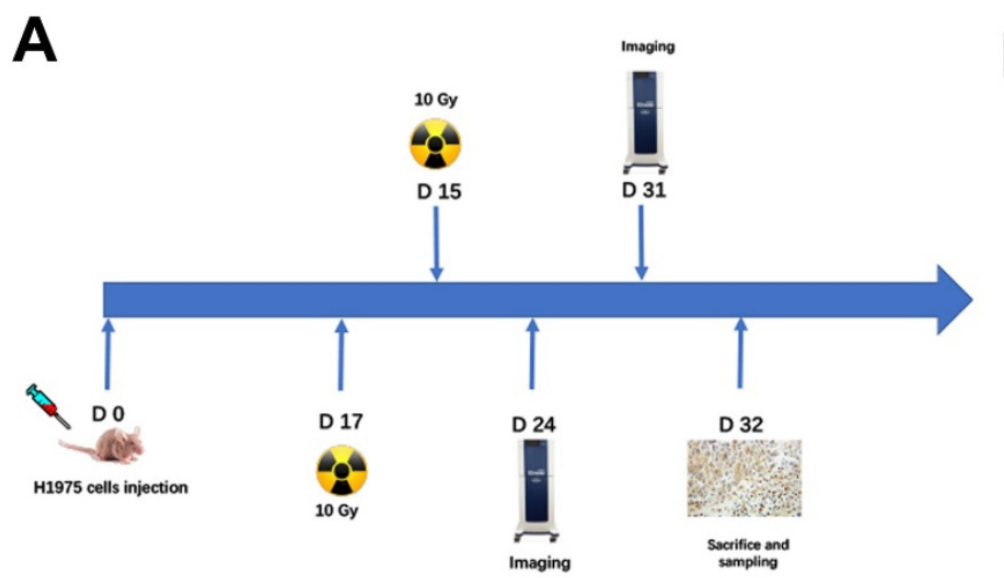

B

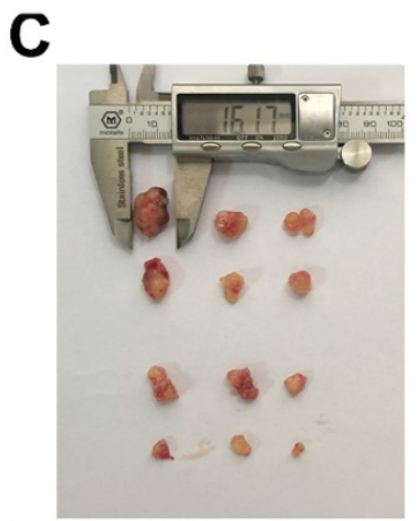

D

E

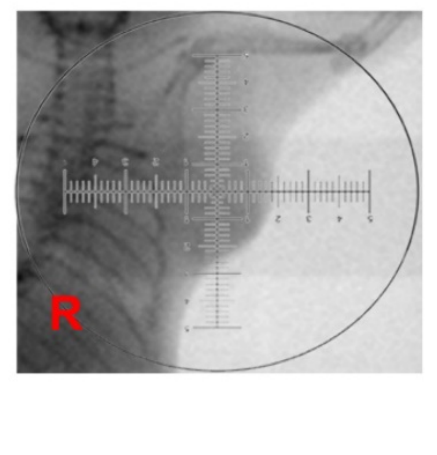

$\mathbf{F}$
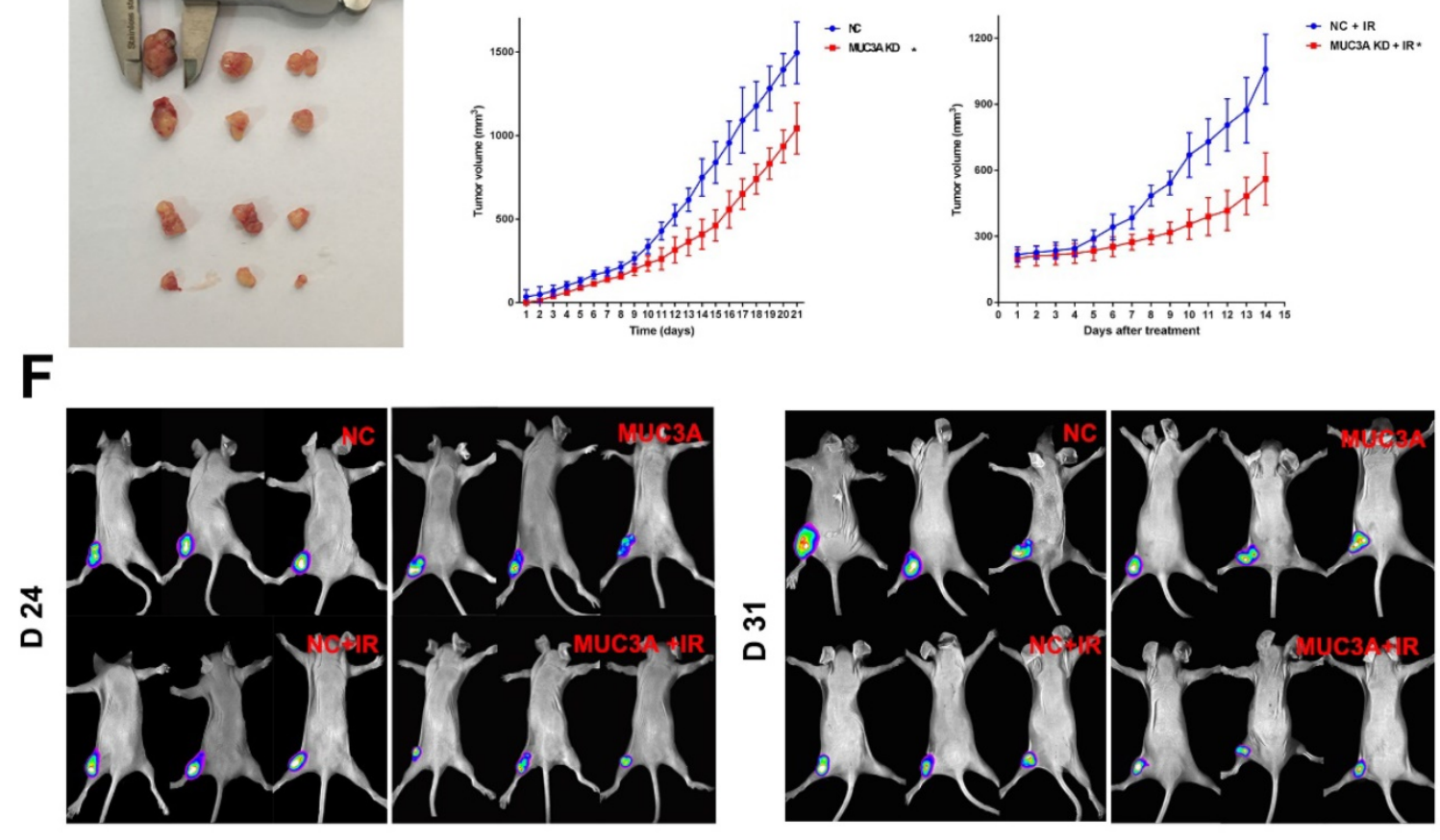

G
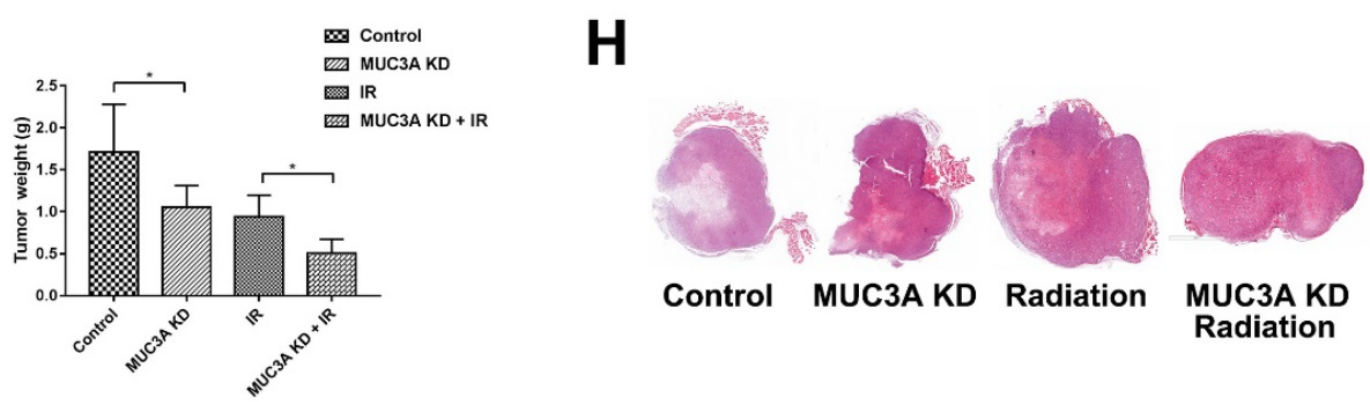

Figure 6. MUC3A knockdown impaired tumor growth and promoted radiosensitivity in vivo. (A) Treatment schema. (B) Gross view of the tumors. (C) Growth curve of tumor volume for the group without radiotherapy. (D) Growth curve of tumor volume for the group with radiotherapy. (E) In vivo imaging of the size and destiny of GFP-H1 975 cells on Days 24 and 31. (F) Tumor weight was significantly different between the control and MUC3A knockdown groups with or without radiotherapy. (G) HE staining was applied to investigate the size and shape of tumor and pathological characters. All the masses were identified as a malignant tumor, and the shapes were similar to $\mathrm{H} 1795$ cells. More necrosis was observed in the control group. *, $\mathrm{p}<0.05$.

MUC3A knockdown upon exposure of X-ray impaired the unclear translocation of $\mathrm{P} 65$ and decreased P65 expression (Figure 7G). MUC3A-wild type cells expressed more P53 in the cytoplasm and 
nucleus, while P53 was rarely expressed in the nucleus of MUC3A-knockdown cells (Figure 7H). On the other hand, the groups with X-ray treatment, exhibited the significant up regulation of P53 in both MUC3A-wild type and MUC3A-knockdown cells. Furthermore, the nucleus location of P53 was less in MUC3A-knockdown cells.

\section{Discussion}

MUC3A is a membrane-associated MUC with abnormal expression in various cancers and may involve in tumorigenesis and progression [27]. Our results and public database also bolster the capacity for MUC3A to predict the clinical outcomes of NSCLC. The mechanism of MUC3A upregulation in cancers remains unclear. It was reported that a conserved TFLK motif and hypoxia tumor microenvironment were attributed to MUC3A expression. MUC3A share the same sperm protein, enterokinase, and agrin domain with MUC1, suggesting that its autoproteolysis may affect cell migration and PI3K-Akt pathway activation by EGF family phosphorylation [20].
A

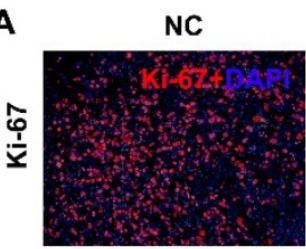

B

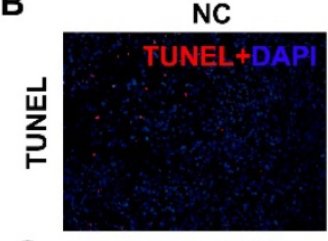

C

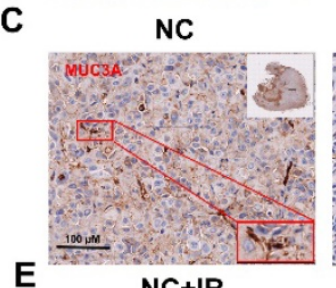

E

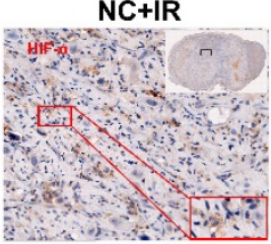

G

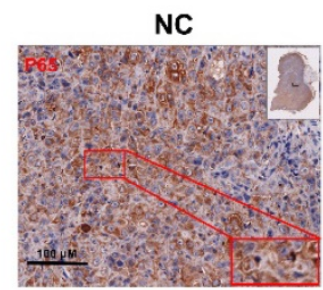

H

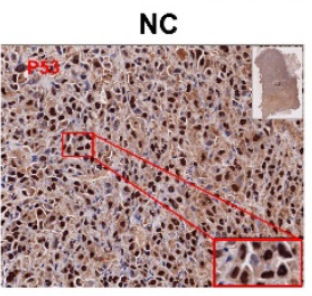

MUC3A KD

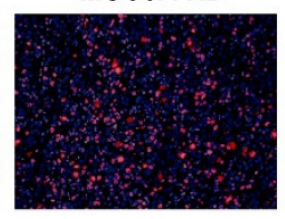

MUC3A KD

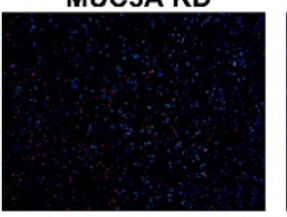

MUC3A KD
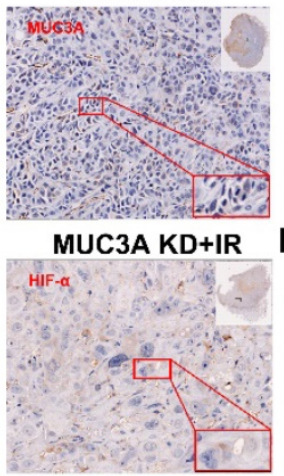

MUC3A KD

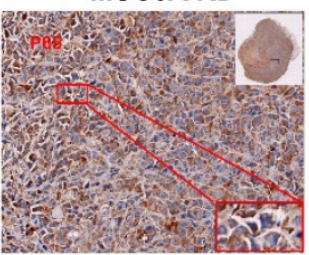

MUC3A KD

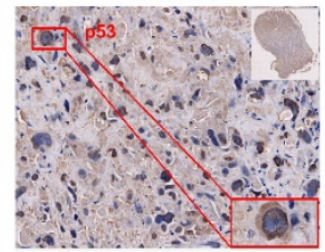

IR

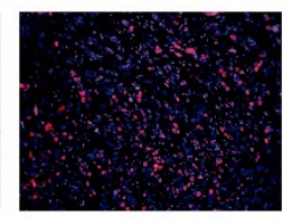

IR

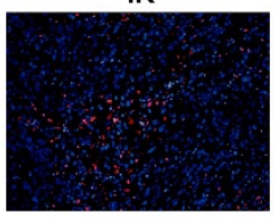

NC
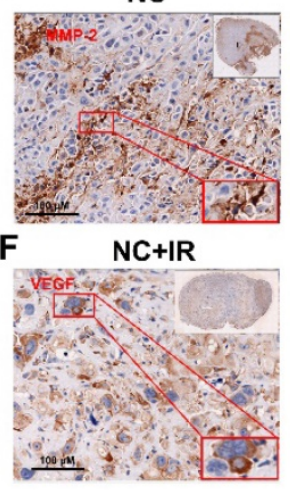

$\mathrm{NC}+\mathrm{IR}$

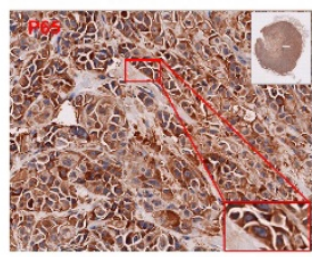

NC+IR

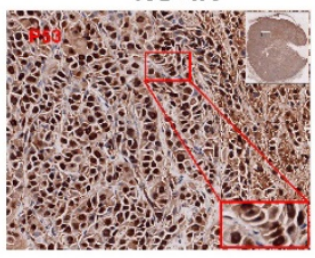

MUC3A+IR

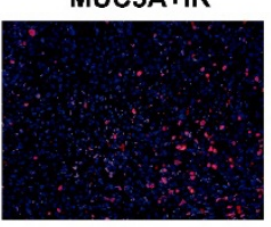

MUC3A+IR

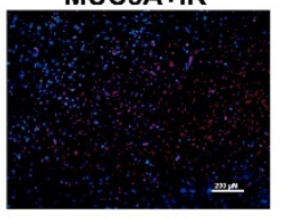

MUC3A KD

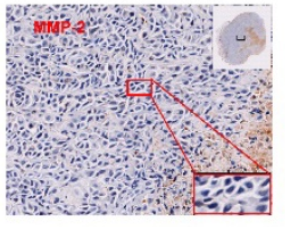

MUC3A KD+IR

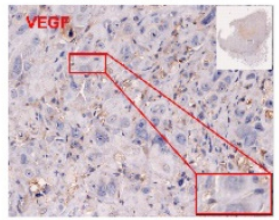

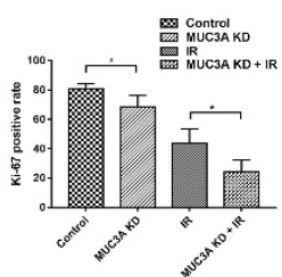
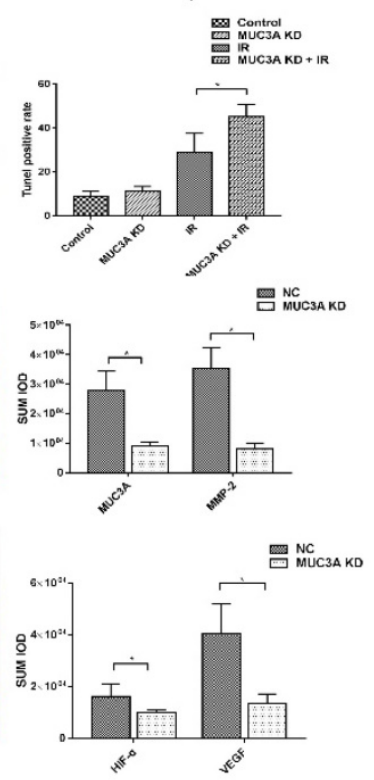

Figure 7. Knockdown of MUC3A presented a comprehensive anti-tumor effect in vivo. (A) Representative images of Ki-67 IF staining in tumor tissues. (B) Representative images of TUNEL staining in tumor tissues. (C) Representative IHC images of MUC3A. The MUC3A knockdown cells had less MUC3A expression than the control. (D) Representative IHC images of MMP2. (E) Representative IHC images of HIFI a. (F) Representative IHC images of VEGF. (G) Representative IHC images of P65. (H) Representative IHC images of TP53. *, $\mathrm{p}<0.05$. 
In the MUC3A-knockdown model, we observed that cell growth was inhibited in vitro and in vivo. Herein, we demonstrated that MUC3A knockdown interfere with the cell cycle process as well. Previous studies have reported that cyclinD1 is one of the downstream gene of $\mathrm{NFKB}$ regulating the G1/S transit via downregulating the CDK4/6, which induces cell accumulated in G1/S phase [28, 29]. FACS results presented $S$ phase were manifestly reduced when MUC3A knockdown along with decreased expression of CyclinD1, CDK4/6. Our finding suggests that MUC3A promotes cell proliferation by aberrant regulation of the G1/S checkpoint.

RELA, also called P65, a critical member of NFkB unit, was observed to interfere with MUC3A in the present study. NFKB is a regulator to control cell growth and survival and constitutively active in various human malignant tumors [28, 30-33]. P65 nucleus translocation and phosphorylation are two crucial behaviors of the canonical activation process of the NFKB pathway [34-36]. In MUC3A-knockdown model, under TNF stimulation, the NFKB-p65 nucleus translocation was dramatically impaired.

Meanwhile, both p-NFkB-p65 (Ser276) and p-NFkB-p65 (Ser536) were dephosphorylated in the cytoplasm and nucleus. Furthermore, we investigated more IкB protein bound to P65 and MUC3A may contribute to maintaining the phosphorylation of P65. Therefore, p-NFkB-p65 (Ser276) was dephosphorylated in MUC3A knockdown cells and enhanced the stability of the P65/IKB $\beta$ complex. These findings indicate that the interaction of MUC3A and P65 is essential to phosphorylate and nucleus translocation of P65, thus mediates NFKB activation in NSCLC cells.

High energy X-rays inflict cellular damages directly via ionizing water molecules and producing hydroxyl radicals to attack the DNA [37]. The X-rays can induce various forms of DNA damage, and DSBs are determinants of cellular radiosensitivity. However, 53BP1, GADD45, and $\gamma \mathrm{H} 2 \mathrm{AX}$ are the indexes that exhibit DNA linkage and reflect DNA damage [38-41]. Additionally, homologous recombinational repair (HRR) and non-homologous end-joining (NHEJ) are two major pathways to repair DSBs. In mammalian cells, HRR prefers to DSBs, BRCA/Rad51 axis is active by p-ATM and plays a vital role in repairing DNA damage [42, 43]; our findings indicated a noticeable interruption of the BRCA/Rad51 axis. In addition, XRCCs are involved in NHEJ, and MUC3A knockdown also attenuates XRCCs in NSCLC cells [44]. In this study, MUC3A knockdown remarkably downregulated BRCA1 and RAD51 translocation, suggesting that the radiosensitivity was promoted by suppression of DNA damage repair and activation of pro-apoptotic proteins. Together, these findings revealed a potential mechanism for radiosensitive enhancement.

As we know, the activation of p53 can occur in response to DNA damage. Ionizing radiation induced DSB triggers p53 activated with a rapid accumulated around DNA foci and mediate transcriptional activation which promotes cell-cycle arrest, apoptosis, or DNA repair [45-48]. In our study, we observed that MUC3A knockdown impair P53 nuclear translocation. P53 is binding to 53BP1 rapidly when DSS generated, then provide a repair platform for DDR. As previously described, the function of BRCA/ Rad51 axis and NHEJ were significantly interrupted, which was attribute to loss-of-function P53.

Furthermore, we noted that MUC3A would induce angiogenesis in NSCLC via elevating the expression of VEGF. In this study, we assume VEGF was regulated in two ways: NFKB signaling induces angiogenesis by increasing the production of VEGF [49-51], and radiation-mediated hypoxia triggers HIF-1a transcription and upregulates VEGF expression [51,52]. MUC3A knockdown may enhance radiosensitivity by promoting oxygen stress and impair HIF-1 $\alpha$ and VEGF expression levels.

MMP-2 and MMP-9 are also known to stimulate tumor angiogenesis and EMT through partial proteolysis of the ECM [53-57]. Our results failed to illustrate NSCLC cells' EMT; however, cell-cell attachment showed closer in MUC3A knockdown cells. The alterations suggest that MUC3A promotes the migration and invasion of NSCLC cells in various ways. We found that high MUC3A expression was a trend to indicate more lymph node metastasis.

In conclusion, our studies indicated that MUC3A promoted tumorigenesis via activating the NFKB pathway and impaired $\mathrm{X}$-rays response via interrupting DNA damage repair. Its high expression was associated with unfavorable clinical outcomes in patients with lung adenocarcinoma, who should be more frequent follow-up and benefit less from radiotherapy. While targeting the MUC3A protein inhibition or deletion may contribute to enhance survival and suppression of lung tumorigenesis.

\section{Supplementary Material}

Supplementary figures and table.

http://www.ijbs.com/v17p2523s1.pdf

\section{Acknowledgements}

This study was supported by National Natural Science Foundation of China (81773236, 81800429 and 81972852), Key Research \& Development Project of Hubei Province (2020BCA069), Nature Science Foundation of Hubei Province (2020CFB612), Health 
Commission of Hubei Province Medical Leading Talent Project, Young and Middle-Aged Medical Backbone Talents of Wuhan (WHQG201902), Application Foundation Frontier Project of Wuhan (2020020601012221), Zhongnan Hospital of Wuhan University Science, Technology and Innovation Seed Fund (znpy2019001, znpy2019048, and ZNJC201922), Chinese Society of Clinical Oncology TopAlliance Tumor Immune Research Fund (Y-JS2019-036), Natural Science Foundation of Fujian Province, (No. 2020J01126), the Startup Fund of Fujian Medical University (No.2018QH1164), Health Commission of Fujian Province Young \& Middle-Aged Medical Backbone Talents Project (2020GGA077), and the Scientific Fund of Sanming Science and Technology Bureau (N0.2018-5-1(7)).

\section{Competing Interests}

The authors have declared that no competing interest exists.

\section{References}

1. Torre LA, Bray F, Siegel RL, Ferlay J, Lortet-Tieulent J, Jemal A. Global cancer statistics, 2012. CA Cancer J Clin. 2015; 65: 87-108.

2. Siegel RL, Miller KD, Jemal A. Cancer statistics, 2016. CA Cancer J Clin. 2016; 66: 7-30

3. Politi K, Herbst RS. Lung cancer in the era of precision medicine. Clin Cancer Res. 2015; 21: 2213-20.

4. Chen W, Zheng R, Baade PD, Zhang S, Zeng H, Bray F, et al. Cancer statistics in China, 2015. CA Cancer J Clin. 2016; 66: 115-32.

5. Lazzari C, Bulotta A, Ducceschi M, Vigano MG, Brioschi E, Corti F, et al. Historical Evolution of Second-Line Therapy in Non-Small Cell Lung Cancer. Front Med (Lausanne). 2017; 4: 4

6. Auperin A, Le Pechoux C, Rolland E, Curran WJ, Furuse K, Fournel P, et al. Meta-analysis of concomitant versus sequential radiochemotherapy in locally advanced non-small-cell lung cancer. J Clin Oncol. 2010; 28: 2181-90.

7. Machtay M, Paulus R, Moughan J, Komaki R, Bradley JE, Choy H, et al. Defining local-regional control and its importance in locally advanced non-small cell lung carcinoma. J Thorac Oncol. 2012; 7: 716-22.

8. De Ruysscher D, Faivre-Finn C, Nestle U, Hurkmans CW, Le Pechoux C, Price A, et al. European Organisation for Research and Treatment of Cancer recommendations for planning and delivery of high-dose, high-precision radiotherapy for lung cancer. J Clin Oncol. 2010; 28: 5301-10.

9. Le Chevalier T, Arriagada R, Quoix E, Ruffie P, Martin M, Tarayre M, et al. Radiotherapy alone versus combined chemotherapy and radiotherapy in nonresectable non-small-cell lung cancer: first analysis of a randomized trial in 353 patients. J Natl Cancer Inst. 1991; 83: 417-23.

10. Martel MK, Ten Haken RK, Hazuka MB, Kessler ML, Strawderman M, Turrisi AT, et al. Estimation of tumor control probability model parameters from 3-D dose distributions of non-small cell lung cancer patients. Lung Cancer. 1999; 24: 31-7

11. Van Klinken BJ, Einerhand AW, Buller HA, Dekker J. Strategic biochemical analysis of mucins. Anal Biochem. 1998; 265: 103-16.

12. Kufe DW. Mucins in cancer: function, prognosis and therapy. Nat Rev Cancer. 2009; 9: 874-85.

13. Awaya $\mathrm{H}$, Takeshima $\mathrm{Y}$, Yamasaki M, Inai $\mathrm{K}$. Expression of MUC1, MUC2 MUC5AC, and MUC6 in atypical adenomatous hyperplasia, bronchioloalveolar carcinoma, adenocarcinoma with mixed subtypes, and mucinous bronchioloalveolar carcinoma of the lung. Am J Clin Pathol. 2004; 121: 644-53.

14. Situ D, Wang J, Ma Y, Zhu Z, Hu Y, Long H, et al. Expression and prognostic relevance of MUC1 in stage IB non-small cell lung cancer. Med Oncol. 2011; 28 Suppl 1: S596-604.

15. Wu G, Kim D, Kim JN, Park S, Maharjan S, Koh H, et al. A Mucin1 C-terminal Subunit-directed Monoclonal Antibody Targets Overexpressed Mucin1 in Breast Cancer. Theranostics. 2018; 8: 78-91.

16. Tsutsumida H, Goto M, Kitajima S, Kubota I, Hirotsu Y, Wakimoto J, et al. MUC4 expression correlates with poor prognosis in small-sized lung adenocarcinoma. Lung Cancer. 2007; 55: 195-203.

17. Yu CJ, Shih JY, Lee YC, Shun CT, Yuan A, Yang PC. Sialyl Lewis antigens: association with MUC5AC protein and correlation with post-operative recurrence of non-small cell lung cancer. Lung Cancer. 2005; 47: 59-67.
18. Gum JR, Jr, Ho JJ, Pratt WS, Hicks JW, Hill AS, Vinall LE, et al. MUC3 human intestinal mucin. Analysis of gene structure, the carboxyl terminus, and a novel upstream repetitive region. J Biol Chem. 1997; 272: 26678-86.

19. Copin MC, Devisme L, Buisine MP, Marquette CH, Wurtz A, Aubert JP, et al. From normal respiratory mucosa to epidermoid carcinoma: expression of human mucin genes. Int J Cancer. 2000; 86: 162-8.

20. Duncan TJ, Watson NF, Al-Attar AH, Scholefield JH, Durrant LG. The role of MUC1 and MUC3 in the biology and prognosis of colorectal cancer. World J Surg Oncol. 2007; 5: 31

21. Park HU, Kim JW, Kim GE, Bae HI, Crawley SC, Yang SC, et al. Aberrant expression of MUC3 and MUC4 membrane-associated mucins and sialyl Le(x) antigen in pancreatic intraepithelial neoplasia. Pancreas. 2003; 26: e48-54.

22. Rakha EA, Boyce RW, Abd El-Rehim D, Kurien T, Green AR, Paish EC, et al. Expression of mucins (MUC1, MUC2, MUC3, MUC4, MUC5AC and MUC6) and their prognostic significance in human breast cancer. Mod Pathol. 2005; 18: $1295-304$.

23. Wang RQ, Fang DC. Alterations of MUC1 and MUC3 expression in gastric carcinoma: relevance to patient clinicopathological features. J Clin Pathol. 2003; 56: 378-84

24. Shibahara H, Higashi M, Yokoyama S, Rousseau K, Kitazono I, Osako M, et al. A comprehensive expression analysis of mucins in appendiceal carcinoma in a multicenter study: MUC3 is a novel prognostic factor. PLoS One. 2014; 9: e115613.

25. Arul GS, Moorghen M, Myerscough N, Alderson DA, Spicer RD, Corfield AP. Mucin gene expression in Barrett's oesophagus: an in situ hybridisation and immunohistochemical study. Gut. 2000; 47: 753-61.

26. Paulsen RD, Soni DV, Wollman R, Hahn AT, Yee MC, Guan A, et al. A Genome-wide siRNA Screen Reveals Diverse Cellular Processes and Pathways that Mediate Genome Stability. Mol Cell. 2009; 35: 228-39.

27. Yonezawa S, Higashi M, Yamada N, Yokoyama S, Kitamoto S, Kitajima S, et al. Mucins in human neoplasms: clinical pathology, gene expression and diagnostic application. Pathol Int. 2011; 61: 697-716.

28. Zhong H, Voll RE, Ghosh S. Phosphorylation of NF-kappa B p65 by PKA stimulates transcriptional activity by promoting a novel bivalent interaction with the coactivator CBP/p300. Mol Cell. 1998; 1: 661-71.

29. Zheng K, He Z, Kitazato K, Wang Y. Selective Autophagy Regulates Cell Cycle in Cancer Therapy. Theranostics. 2019; 9: 104-25.

30. Vermeulen L, De Wilde G, Van Damme P, Vanden Berghe W, Haegeman G. Transcriptional activation of the NF-kappaB p65 subunit by mitogen- and stress-activated protein kinase-1 (MSK1). EMBO J. 2003; 22: 1313-24.

31. Geng $\mathrm{H}$, Wittwer $\mathrm{T}$, Dittrich-Breiholz $\mathrm{O}$, Kracht $\mathrm{M}$, Schmitz ML. Phosphorylation of NF-kappaB p65 at Ser468 controls its COMMD1dependent ubiquitination and target gene-specific proteasomal elimination. EMBO Rep. 2009; 10: 381-6.

32. Jang HD, Yoon K, Shin YJ, Kim J, Lee SY. PIAS3 suppresses NF-kappaBmediated transcription by interacting with the p65/RelA subunit. J Biol Chem. 2004; 279: 24873-80.

33. Zhu Y, Zhang M, Luo L, Gill MR, De Pace C, Battaglia G, et al. NF-kappaB hijacking theranostic Pt(ll) complex in cancer therapy. Theranostics. 2019; 9: 2158-66.

34. Hochrainer $\mathrm{K}$, Racchumi G, Zhang S, Iadecola C, Anrather J. Monoubiquitination of nuclear RelA negatively regulates NF-kappaB activity independent of proteasomal degradation. Cell Mol Life Sci. 2012; 69: 2057-73.

35. Higashitsuji H, Higashitsuji H, Nagao T, Nonoguchi K, Fujii S, Itoh K, et al. A novel protein overexpressed in hepatoma accelerates export of NF-kappa B from the nucleus and inhibits p53-dependent apoptosis. Cancer Cell. 2002; 2: $335-46$.

36. Strebovsky J, Walker P, Lang R, Dalpke AH. Suppressor of cytokine signaling 1 (SOCS1) limits NFkappaB signaling by decreasing p65 stability within the cell nucleus. FASEB J. 2011; 25: 863-74

37. Irminger-Finger I, Ratajska M, Pilyugin M. New concepts on BARD1: Regulator of BRCA pathways and beyond. Int J Biochem Cell Biol. 2016; 72: 1-17.

38. Prakash R, Zhang Y, Feng W, Jasin M. Homologous recombination and human health: the roles of BRCA1, BRCA2, and associated proteins. Cold Spring Harb Perspect Biol. 2015; 7: a016600.

39. Kujjo LL, Laine T, Pereira RJ, Kagawa W, Kurumizaka H, Yokoyama S, et al. Enhancing survival of mouse oocytes following chemotherapy or aging by targeting Bax and Rad51. PLoS One. 2010; 5. e9204.

40. Gasparini P, Lovat F, Fassan M, Casadei L, Cascione L, Jacob NK, et al. Protective role of miR-155 in breast cancer through RAD51 targeting impairs homologous recombination after irradiation. Proc Natl Acad Sci U S A. 2014; 111: 4536-41.

41. Barbano R, Copetti M, Perrone G, Pazienza V, Muscarella LA, Balsamo T, et al. High RAD51 mRNA expression characterize estrogen receptor-positive/ progesteron receptor-negative breast cancer and is associated with patient's outcome. Int J Cancer. 2011; 129: 536-45.

42. Pace P, Mosedale G, Hodskinson MR, Rosado IV, Sivasubramaniam M, Patel KJ. Ku70 corrupts DNA repair in the absence of the Fanconi anemia pathway. Science. 2010; 329: 219-23.

43. Li H, Vogel H, Holcomb VB, Gu Y, Hasty P. Deletion of Ku70, Ku80, or both causes early aging without substantially increased cancer. Mol Cell Biol. 2007; 27: $8205-14$ 
44. Goudelock DM, Jiang K, Pereira E, Russell B, Sanchez Y. Regulatory interactions between the checkpoint kinase Chk1 and the proteins of the DNA-dependent protein kinase complex. J Biol Chem. 2003; 278: 29940-7.

45. Reinhardt HC, Aslanian AS, Lees JA, Yaffe MB. p53-deficient cells rely on ATM- and ATR-mediated checkpoint signaling through the p38MAPK/MK2 pathway for survival after DNA damage. Cancer Cell. 2007; 11: 175-89.

46. Bieging KT, Attardi LD. Cancer: A piece of the p53 puzzle. Nature. 2015; 520: 37-8.

47. Gajewski S, Hartwig A. PARP1 Is Required for ATM-Mediated p53 Activation and p53-Mediated Gene Expression after Ionizing Radiation. Chem Res Toxicol. 2020; 33: 1933-40.

48. Li Q, Karim RM, Cheng M, Das M, Chen L, Zhang C, et al. Inhibition of p53 DNA binding by a small molecule protects mice from radiation toxicity. Oncogene. 2020; 39: 5187-200.

49. Lee JC, Tae HJ, Kim IH, Cho JH, Lee TK, Park JH, et al. Roles of HIF-1alpha, VEGF, and NF-kappaB in Ischemic Preconditioning-Mediated Neuroprotection of Hippocampal CA1 Pyramidal Neurons Against a Subsequent Transient Cerebral Ischemia. Mol Neurobiol. 2017; 54: 6984-98.

50. Mo SJ, Hong J, Chen X, Han F, Ni Y, Zheng Y, et al. VEGF-mediated NF-kappaB activation protects PC12 cells from damage induced by hypoxia. Neurosci Lett. 2016; 610: 54-9.

51. Li Y, Sui H, Jiang C, Li S, Han Y, Huang P, et al. Dihydroartemisinin Increases the Sensitivity of Photodynamic Therapy Via NF-kappaB/HIF-1alpha/VEGF Pathway in Esophageal Cancer Cell in vitro and in vivo. Cell Physiol Biochem. 2018; 48: 2035-45.

52. Zhang X, Qi Z, Yin H, Yang G. Interaction between p53 and Ras signaling controls cisplatin resistance via HDAC4- and HIF-1alpha-mediated regulation of apoptosis and autophagy. Theranostics. 2019; 9: 1096-114.

53. Vandooren J, Van den Steen PE, Opdenakker G. Biochemistry and molecular biology of gelatinase B or matrix metalloproteinase-9 (MMP-9): the next decade. Crit Rev Biochem Mol Biol. 2013; 48: 222-72.

54. Kobayashi T, Kim H, Liu X, Sugiura H, Kohyama T, Fang Q, et al. Matrix metalloproteinase-9 activates TGF-beta and stimulates fibroblast contraction of collagen gels. Am J Physiol Lung Cell Mol Physiol. 2014; 306: L1006-15.

55. Tranchant I, Vera L, Czarny B, Amoura M, Cassar E, Beau F, et al. Halogen bonding controls selectivity of FRET substrate probes for MMP-9. Chem Biol. 2014; 21: 408-13.

56. Apoorv TS, Babu PP, Meese S, Gai PP, Bedu-Addo G, Mockenhaupt FP. Matrix metalloproteinase-9 polymorphism $1562 \mathrm{C}>\mathrm{T}$ (rs3918242) associated with protection against placental malaria. Am J Trop Med Hyg. 2015; 93: 186-8.

57. Li M, Yang G, Xie B, Babu K, Huang C. Changes in matrix metalloproteinase-9 levels during progression of atrial fibrillation. J Int Med Res. 2014; 42: 224-30. 